\title{
Seismic Performance of Modular Structures with Novel Steel Frame: Light Gauge Slotted Steel Stud Walls
}

\author{
Chao Gong, ${ }^{1}$ Dawei Sun, ${ }^{2,3}$ Qixian Chen, ${ }^{2,3}$ Yong Zhu $\mathbb{D}^{1,3}$ Mingxu Shang, ${ }^{2,3}$ and Faqi Liu ${ }^{2,3}$ \\ ${ }^{1}$ Central Research Institute of Building and Construction Co., Ltd., MCC, Beijing 100088, China \\ ${ }^{2}$ School of Civil Engineering, Harbin Institute of Technology, Harbin 150090, China \\ ${ }^{3}$ Key Lab of Smart Prevention and Mitigation of Civil Engineering Disasters of the Ministry of \\ Industry and Information Technology, Harbin Institute of Technology, Harbin 150090, China \\ Correspondence should be addressed to Yong Zhu; zhuyong@stu.hit.edu.cn
}

Received 5 November 2021; Revised 4 December 2021; Accepted 10 January 2022; Published 3 February 2022

Academic Editor: Luigi Di Sarno

Copyright (c) 2022 Chao Gong et al. This is an open access article distributed under the Creative Commons Attribution License, which permits unrestricted use, distribution, and reproduction in any medium, provided the original work is properly cited.

\begin{abstract}
Modular structures are premanufactured off-site and assembled on-site, leading to reduced on-site works and construction periods and improved quality compared to conventional prefabricated steel structures and reinforced concrete structures. Meanwhile, steel frame-light gauge slotted steel stud (LGSS) walls have been considered to be assembled into the modules due to their excellent thermal- and sound-insulation properties. These structural components will also contribute to the resistance of the modular system when subjected to lateral loads/actions, especially seismic actions. A finite element model was developed to investigate the seismic performance of high-rise modular steel structures with LGSS shear walls. Then, parametric studies were conducted to investigate the influences of the layouts of the LGSS shear walls and structure heights on the lateral stiffness, the deformation modes, and the stress states of the modular steel structures. Observed from the results of a ten-storey modular steel structure infilled with LGSS shear walls, the maximum storey drift reduced by $50.1-79.50 \%$ compared to the corresponding pure steel frame structure under the selected high-intensity seismic waves. The results indicate that the studied modular steel structure with LGSS shear walls possesses good seismic resistance and could be a practical and economical choice for future modular constructions.
\end{abstract}

\section{Introduction}

Modular constructions have gained increasing interest from designers, researchers, and engineers in recent decades [1-4]. Modules, the basic units of modular structures, are commonly designed to the demands, prefabricated in factories, transported to the desired construction sites, and then assembled into the designed structures, as shown in Figure 1. Compared to the conventional on-site construction techniques and other prefabricated construction technologies, modular structures possess a higher-level prefabrication rate (approximate 70\%-95\%) and are more convenient (fewer on-site works), time-saving, and environmental-friendly. Thus, they are ideal for buildings designed with repetitive architectural plans and structural layouts [1]. To date, extensive low-rise modular buildings have been constructed and the modular construction techniques are gradually applied for the constructions of mid-rise and high-rise buildings, such as the 60-storey Collins House in Melbourne (height: $184 \mathrm{~m}$ ).

Since the modular components and the volumetric modules are designed and manufactured in standardised factories, they are commonly well guaranteed to withstand typical loads/actions, such as self-weights and various axial live loads. The key to ensuring structural integrity [5-14] becomes joints/connections, which attracts wide attention from engineers and researchers. Further, the performance of the assembled modular structures has also been mainly focused on the performance under seismic actions and some other transverse loads/actions [15-33]. Thus, extensive investigations have been reported, providing a clear understanding of the behaviour of modular 


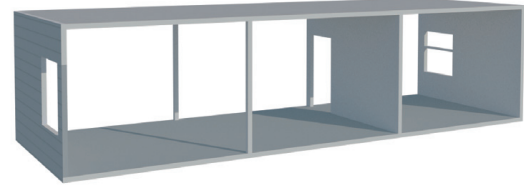

(a)

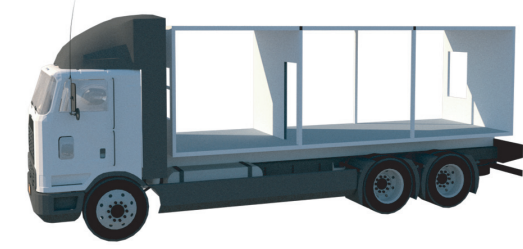

(b)

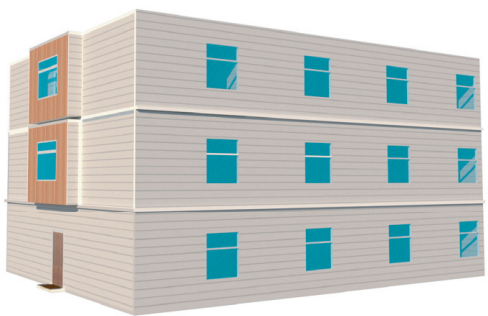

(d)

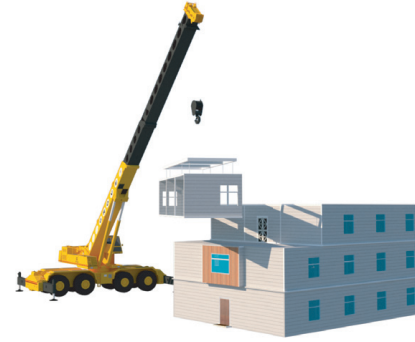

(c)

Figure 1: Process of modular constructions. (a) Module component. (b) Transportation. (c) Hoisting and construction. (d) Construction completed.

structures based on these three levels (i.e., single modular component and module level, the joint and connection level, and the assembled modular structural system level). Further, some of these studies [17,29-32] indicate that the lateral stiffness can also be improved by employing some novel prefabricated shear wall members.

In this context, the seismic performance of multistorey modular structures with novel light gauge slotted steel stud (LGSS) walls, which have been employed in modular buildings in China due to their excellent thermal- and sound-insulation properties and mechanical properties $[33,34]$, was investigated systematically using the finite element methodology. This study started from the verification of the simplified models proposed for LGSS walls and joints between modules. Comparing the relevant experimental data obtained from literature and the FE results, a bar-spring model developed by Ye et al. [33] was finally adopted for the LGSS walls, and the hinge assumption [5] was then adopted for the joints. Based on these simplifications, an FE model was developed for analysing the behaviour of modular steel structures with LGSS walls under high-intensity seismic waves (two recorded seismic waves and one simulated wave were included). Parametric studies were then conducted to investigate the influences of the structure heights, the presence of the LGSS walls and the arrangement characteristics of the LGSS walls on the lateral stiffness, the internal force distributions, and the deformation modes of the modular steel structures.

\section{Verification of the Simplified Models for LGSS Walls and Joints between Modules}

Commonly, appropriate simplifications and assumptions can balance the efficiency and accuracy of the research of the modular structure [35, 36]. Thus, simplified models for LGSS walls and joints between modules were selected and verified in this section, which would be the basis for subsequent structural system-level research.

2.1. Simplification of the Light Gauge Steel Stud (LGSS) Walls. Light gauge steel stud (LGSS) walls, as shown in Figure 2, commonly have light self-weight and excellent thermal- and sound-insulation abilities. The LGSS walls comprise several light-gauge steel studs, tracks, insulation infills, and cover boards, which are convenient to be prefabricated in factories and suitable for forming the volumetric modules. The mechanical performance of the LGSS walls under lateral cyclic loading has been experimentally studied, such as those reported by Ye et al. [33] and Geng et al. [34]. The details of the test specimens in these studies are summarised in Table 1. An equivalent bracing model was also proposed by $\mathrm{Ye}$ et al. [33] to improve the efficiency of the analyses related to LGSS walls, as schematically shown in Figure 3 and calculated as follows.

The force of the inclined rod $\mathrm{AD}\left(F_{t}\right)$ can be obtained by the following equations:

$$
\begin{aligned}
F_{t} & =\frac{\Delta E_{b} A_{b} \cos \theta}{L_{1}}, \\
L_{1} & =\sqrt{L^{2}+H^{2}}, \\
\cos \theta & =\frac{L}{\sqrt{L^{2}+H^{2}}}, \\
F_{t} & =\frac{\Delta E_{b} A_{b} L}{L^{2}+H^{2}},
\end{aligned}
$$

where $H$ and $L$ are the height and the width of the shear wall, respectively, $L_{l}$ is the length of $\mathrm{AD}, P$ is the lateral 


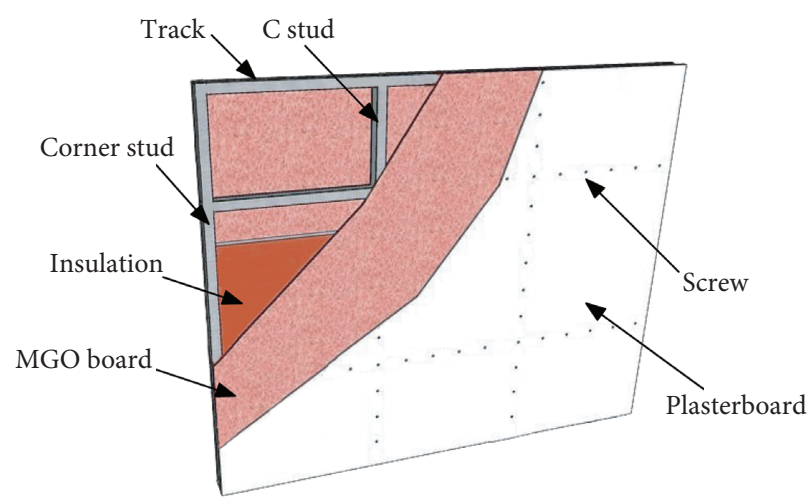

Figure 2: Light gauge steel stud walls.

TABLE 1: Details of the experimental studies conducted on the lateral resistance of LGSS walls.

\begin{tabular}{|c|c|c|c|c|c|c|}
\hline \multicolumn{7}{|c|}{ Dimensions (mm) } \\
\hline Specimen & $\begin{array}{c}\text { Overall } \\
(\text { length } \times \text { height })\end{array}$ & $\begin{array}{l}\text { Hole on the wall } \\
\text { (length } \times \text { height) }\end{array}$ & C studs & Corner studs & Tracks & Origin \\
\hline WA1 & \multirow{3}{*}{$3600 \times 3000$} & \multirow{3}{*}{-} & $\mathrm{C} 89 \times 50 \times 13$ & $\square 89 \times 100 \times 0.9$ & $\mathrm{U} 91 \times 50$ & \multirow{9}{*}{$\begin{array}{c}\text { Ye et al. } \\
{[33]}\end{array}$} \\
\hline WA2 & & & $\mathrm{C} 89 \times 50 \times 13$ & $\square 89 \times 100 \times 0.9$ & U91 × 50 & \\
\hline WA3 & & & $\begin{array}{c}\text { Double } \\
\mathrm{C} 89 \times 50 \times 13\end{array}$ & $\square 89 \times 100 \times 0.9$ & $\mathrm{U} 91 \times 50$ & \\
\hline WB1 & \multirow{3}{*}{$2100 \times 3000$} & \multirow{3}{*}{-} & $\begin{array}{c}\text { Double } \\
\mathrm{C} 140 \times 50 \times 13\end{array}$ & $\square 140 \times 140 \times 1.5$ & $\mathrm{U} 142 \times 50$ & \\
\hline WB2 & & & $\mathrm{C} 140 \times 50 \times 13$ & $\square 140 \times 140 \times 1.5$ & $\mathrm{U} 142 \times 50$ & \\
\hline WB3 & & & $\mathrm{C} 140 \times 50 \times 13$ & $\square 140 \times 140 \times 1.5$ & $\mathrm{U} 142 \times 50$ & \\
\hline WC1 & \multirow{3}{*}{$3600 \times 3000$} & $1500 \times 1500$ & $\mathrm{C} 140 \times 50 \times 13$ & $\square 140 \times 140 \times 1.5$ & $\mathrm{U} 142 \times 50$ & \\
\hline WC2 & & \multirow{2}{*}{$1500 \times 2400$} & $\mathrm{C} 140 \times 50 \times 13$ & $\square 140 \times 140 \times 1.5$ & $\mathrm{U} 142 \times 50$ & \\
\hline WC3 & & & $\mathrm{C} 140 \times 50 \times 13$ & $\square 140 \times 140 \times 1.5$ & $\mathrm{U} 142 \times 50$ & \\
\hline KJ-1 & \multirow{2}{*}{$3000 \times 3000$} & - & $\mathrm{C} 150 \times 40 \times 15$ & HW $250 \times 250 \times 9 \times 14$ & HW $250 \times 175 \times 7 \times 11$ & Geng et al. \\
\hline $\mathrm{KJ}-2$ & & $1500 \times 1800$ & $\mathrm{C} 150 \times 40 \times 15$ & HW $250 \times 250 \times 9 \times 14$ & HW $250 \times 175 \times 7 \times 11$ & [34] \\
\hline
\end{tabular}
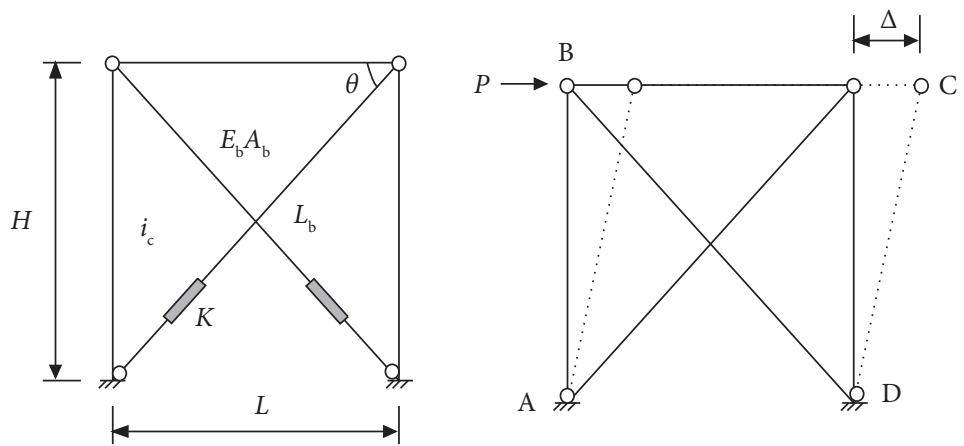

Figure 3: Bar-spring simplified model for light gauge steel stud walls.

force, and $\theta$ is the angle between $A D$ and $B D ; \Delta$ is the corresponding lateral displacement, and $E_{b} A_{b}$ is the axial rigidity of the brace.

Set the angles of the columns $\mathrm{AB}$ and $\mathrm{CD}$ as $\theta_{B}$ and $\theta_{D}$, and set the shear forces of the columns $A B$ and $C D$ as $Q_{A B}$ and $Q_{C D}$, respectively, which can be calculated by equations (5) and (6). According to the horizontal force balance at the bottom of the wall, the corresponding lateral displacement $(\Delta)$ and the lateral stiffness $(K)$ of the shear wall that consider the contribution of the wallboards can be calculated by equations (7)-(9).

$$
\begin{gathered}
\theta_{B}=\theta_{D}=\frac{3 \Delta}{2 H}, \\
Q_{A B}=Q_{C D}=-\frac{3 i_{c} \Delta}{H^{2}},
\end{gathered}
$$




$$
\begin{aligned}
& Q_{A B}+Q_{C D}+P-2 F_{t} \cos \theta=0, \\
& \Delta=\frac{P H^{2}}{3 i_{c}+\left(2 H^{2} L^{2} E_{b} A_{b} /\left(L^{2}+H^{2}\right)^{1.5}\right)}, \\
& K=\frac{P}{\Delta}=\frac{6 i_{c}}{H^{2}}+\frac{2 L^{2} E_{b} A_{b}}{\left(L^{2}+H^{2}\right)^{1.5}}
\end{aligned}
$$

where $i_{\mathrm{c}}$ is the line rigidity of the side studs.

According to the Japanese design code [37], the axial rigidity of the brace of the $i$-layer wallboard $E_{b i} A_{b i}$ can be calculated by (10). For multistorey structures, the lateral stiffness $K$ can be calculated by (11).

$$
\begin{aligned}
& E_{b i} A_{b i}=\frac{1}{2} \frac{\left(H^{2}+L^{2}\right)^{1.5}}{\left(H L / G_{i} t_{i}\right)+\left(2 d / P_{p} n_{s}\right)\left(H^{2}+H L\right)}, \\
& K=\frac{P}{\Delta}=\frac{6 i_{c}}{H^{2}}+\frac{2 L^{2} \sum E_{b i} A_{b i}}{\left(L^{2}+H^{2}\right)^{1.5}}
\end{aligned}
$$

where $G_{\mathrm{i}}$ and $t_{\mathrm{i}}$ are the shear modulus and the thickness of the $i$-layer wallboard; $d$ is the deformation of the screw connection, $P_{p}$ is the ultimate strength of the screw connection, and $n_{\mathrm{s}}$ is the number of the screws along the vertical edge on one side of the wall.

The comparisons between the experimental skeleton hysteresis curve (obtained from the experimental data in the reference literature $[33,34])$ and the predictions of the barspring simplified model are shown in Figure 4. It can be seen that the predictions well matched the test curves, which indicates that the equivalent bracing model is acceptable for predicting the lateral resisting performance of the LGSS walls.

2.2. Simplification of the Joints between Modules. For modular structures, joints and connections are essential for ensuring structural integrality. Meanwhile, many novel joints have also been developed [5-14]. However, the coverplate bolted joints are still widely employed in current constructions, as shown in Figure 5. Commonly, the bolts can be simplified to be tie bars, and the steel plug can be considered using a hinge assumption or a fixed end assumption, as shown in Figure 6. Based on the experimental study for joints between modules presented by Chen et al. [5], as shown in Figure 7, FE models with the hinge end and fixed end assumptions were developed, in which the corner studs and the beams were modelled using beam elements and the tie bars (i.e., the equivalent components for bolts as aforementioned) were modelled using truss elements. The strain-stress relationship model with the strain hardening effect was employed, as shown by equation (12). The steel grade was Q345, whose yield stress was $345 \mathrm{MPa}$. Young's modulus and Poisson's ratio of steel were set to $200 \mathrm{GPa}$ and 0.3 , respectively, and the strain hardening modulus was set to 0.01 times Young's modulus.

$$
\sigma= \begin{cases}E \varepsilon, & \varepsilon \leq \varepsilon_{y}, \\ f_{y}+0.01 E\left(\varepsilon-\varepsilon_{y}\right), & \varepsilon>\varepsilon_{y},\end{cases}
$$

where $\varepsilon$ and $\sigma$ are the strain and the stress of steel, $E$ is the elastic modulus of steel, and $\varepsilon_{y}$ and $f_{y}$ are the yield strain and the yield stress of steel, respectively.

Comparisons between the experimental results and the simulated results showed that the results of the FE model with hinge end assumption generally well matched the test results. Thus, the hinge model was finally adopted in this study to simplify the joints between modules when analysing the performance of multistorey modular structures hereafter.

\section{FE Model Developed for the Modular Structures}

3.1. FE Methodology. Based on the simplifications mentioned above, a FE model was then developed using ABAQUS for multistorey modular steel structures with LGSS walls to investigate their performance under seismic loading. The strainstress relationship model with the consideration of the strain hardening effect was also used for the steel frames of the modules, the same as the material model used for simulating LGSS walls. Considering the efficiency of the FE simulation processes, all the structural members of the module frame were modelled using beam elements. The LGSS walls were modelled with the validated bar-spring model and the joints were assumed to be hinge ends. The other nonstructural components were ignored in the FE model as they commonly have little effect on the mechanical behaviour of the studied modular structures.

To achieve a better understanding of the seismic performance of the studied modular structures, three earthquake waves were selected as the seismic test loads, including two recorded earthquake waves and one simulated earthquake wave, that is, the earthquake waves recorded at Loleta Fire Station of Cape Mendocino earthquake in 1992 and at North Palm Springs Fire Station \#36 of the Landers earthquake in 1992 and a 40-second simulated earthquake wave generated using the SIMQKE_GR programme. The amplitudes of the selected seismic waves were adjusted before applied, according to the relevant provisions stated in GB50011-2010 [38], as shown in Figure 8 . The maximum acceleration-time histories of frequent earthquakes and rare earthquakes are $70 \mathrm{gal}$ and $400 \mathrm{gal}$, respectively.

\subsection{Benchmark Model}

3.2.1. Details of the Benchmark Model. A 10-storey modular structure model was established as a benchmark model in this study. Based on the volumetric modules developed by Metallurgical Corporation of China (MCC), the dimension was set to $14.4 \mathrm{~m}, 3 \mathrm{~m}$, and $3 \mathrm{~m}$ in length, width, and height of each module, respectively, as shown in Figure 9. The upper and lower beams were manufactured using $\mathrm{H}$-shape wide flange steel HW $150 \times 150 \times 7 \times 10 \mathrm{~mm}$ and narrow flange steel $\mathrm{HN} 300 \times 150 \times 6.5 \times 9 \mathrm{~mm}$, and the columns are made from square hollow sections with a section width of $200 \mathrm{~mm}$ and a 


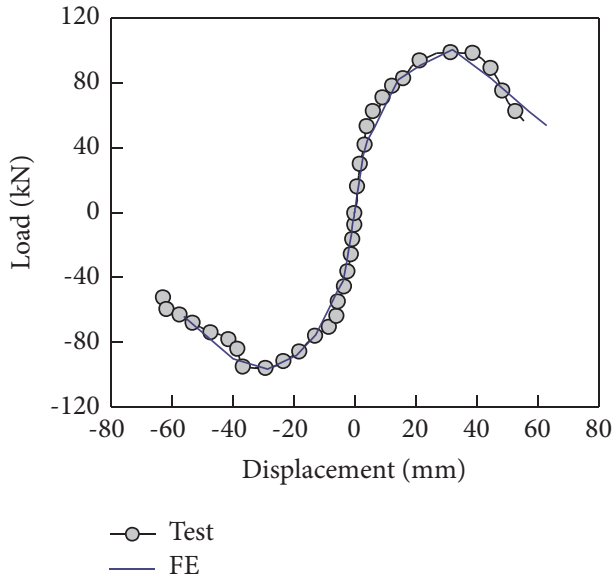

(a)

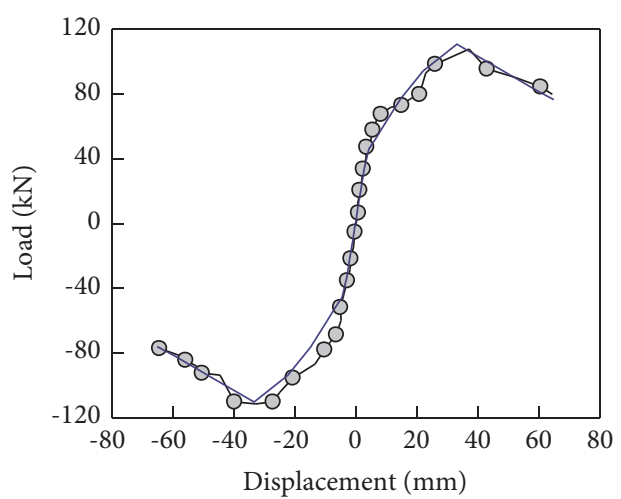

$\multimap-$ Test

— FE

(c)

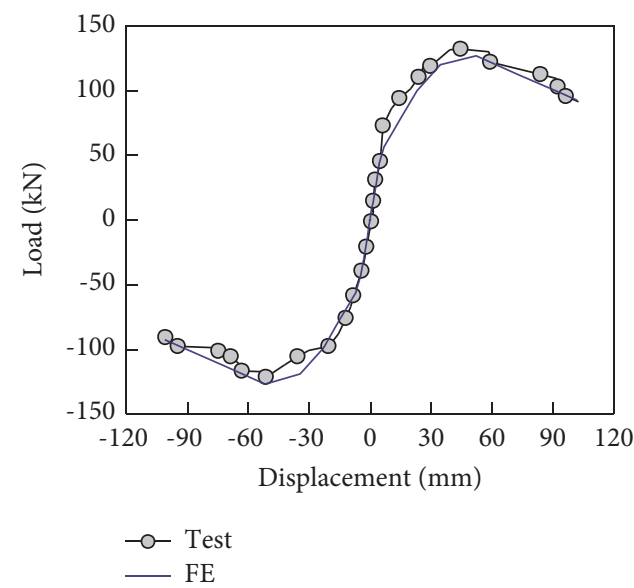

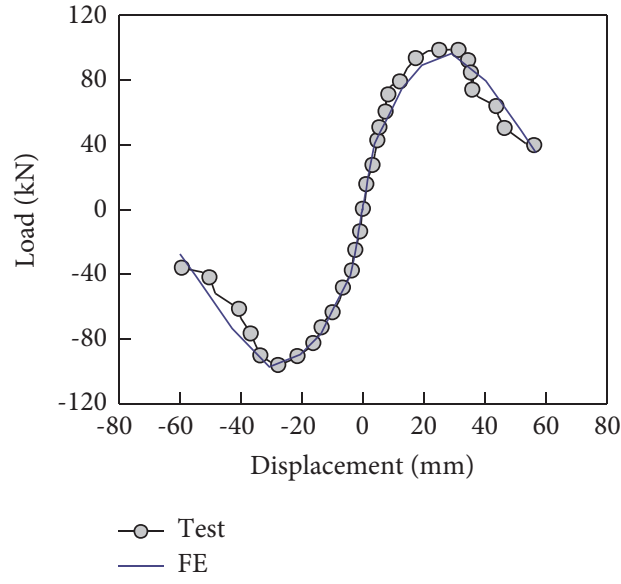

(b)

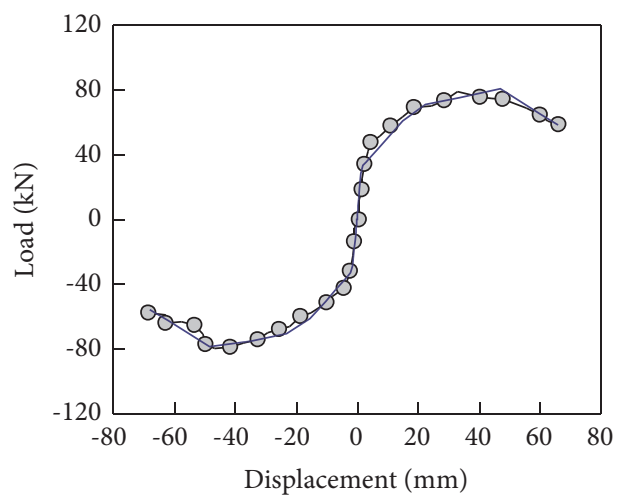

-o- Test

- FE

(d)

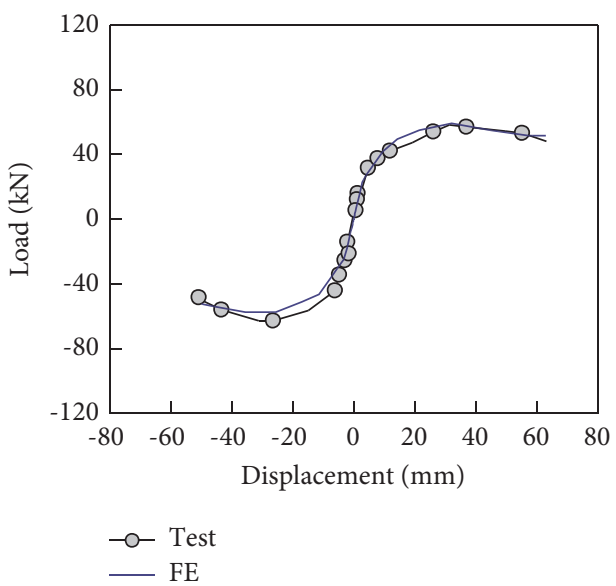

(f)

Figure 4: Continued. 


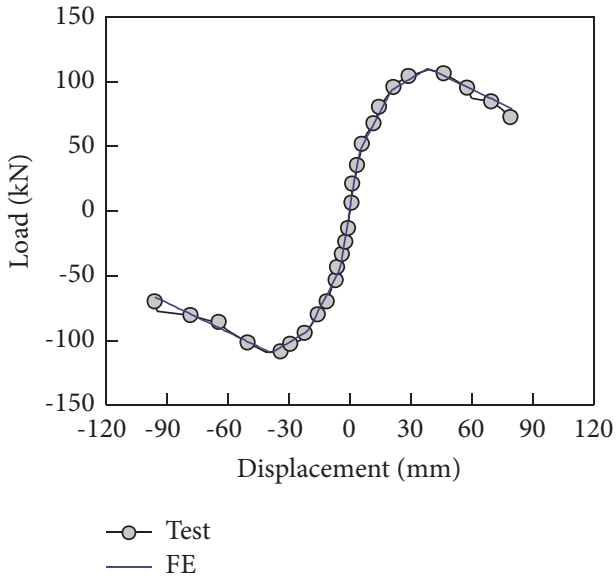

(g)

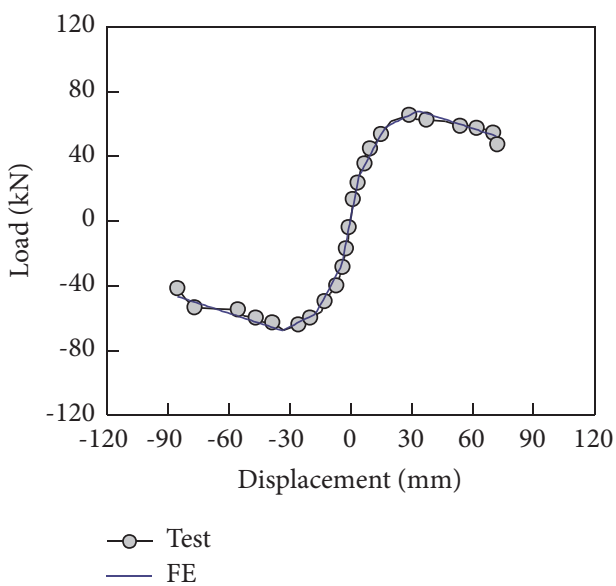

(i)

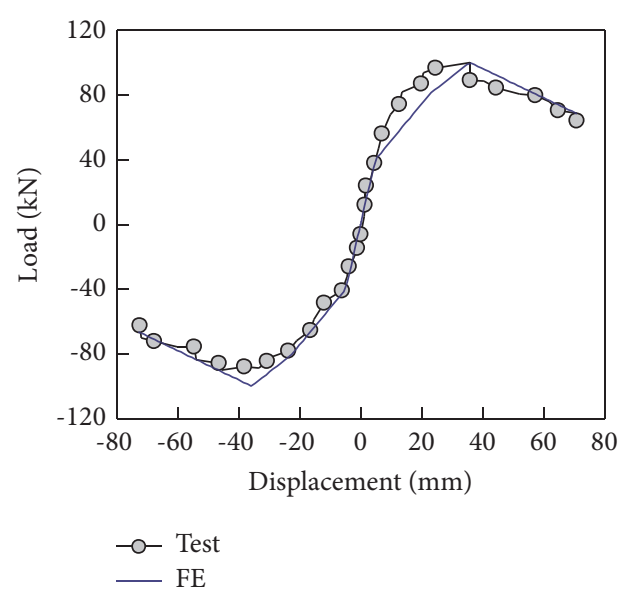

(h)

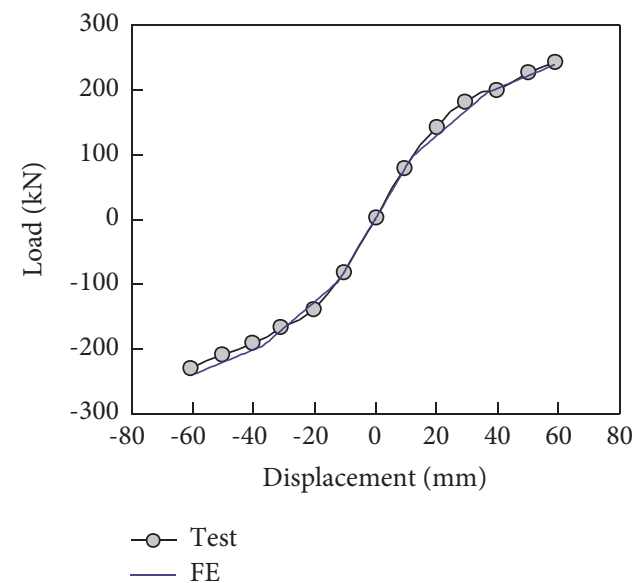

(j)

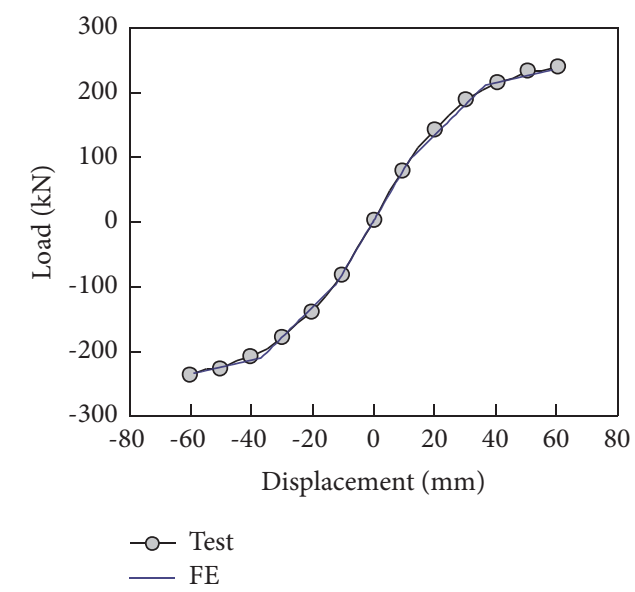

(k)

FIGURE 4: Comparison of the experimental $[33,34]$ and the simulated (using the bar-spring model) skeleton curves of the LGSS walls. (a) WA1. (b) WA2. (c) WA3. (d) WB1. (e) WB2. (f) WB3. (g) WC1. (h) WC2. (i) WC3. (j) KJ-1. (k) KJ-2.

thickness of $8 \mathrm{~mm}$. The grade of these structural steel members was Q345, whose nominal yield stress was $345 \mathrm{MPa}$. Young's modulus and Poisson's ratio of steel were set to $200 \mathrm{GPa}$ and 0.3 , respectively. The benchmark model was assembled with eight modules on each floor and 80 modules in total for the 10-storey modular structure.
The details of the LGSS walls used in the model are shown in Figure 10. The filler LGSS walls herein were assembled by several perforated $\mathrm{C}$ studs $(\mathrm{C} 140 \times 70 \times 15 \times 1 \mathrm{~mm})$, two $\mathrm{U}$ tracks as tie beams $(\mathrm{U} 140 \times 90 \times 1 \mathrm{~mm})$, one-layer plasterboard, and the thermal-insulation infills. To improve the lateral stiffness of the LGSS walls, strengthened LGSS walls were also used 


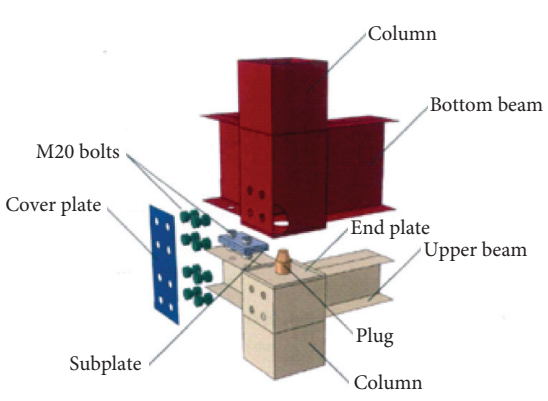

(a)
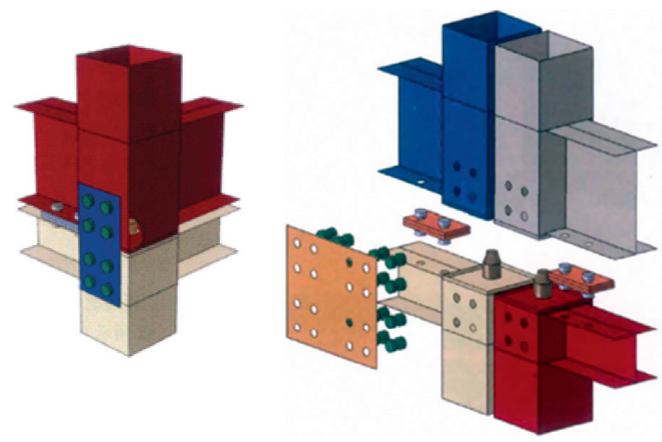

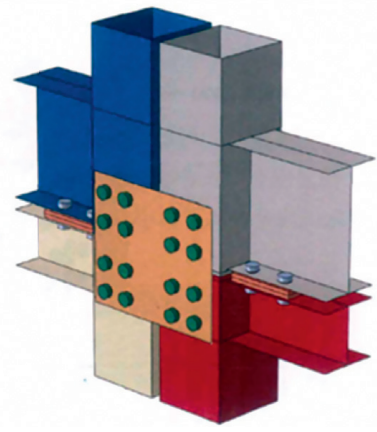

(b)

FIgURE 5: Cover-plate bolted joints [10]. (a) Joints between two modules. (b) Joints between four modules.

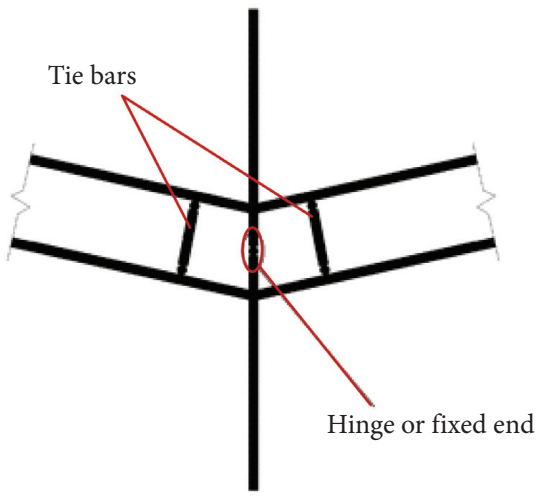

(a)

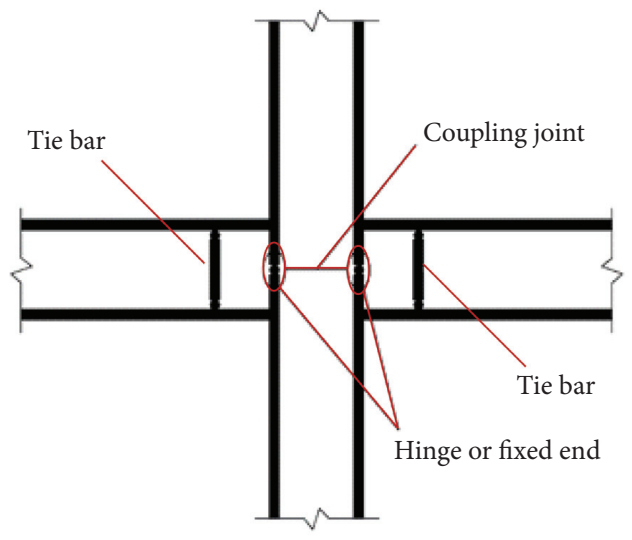

(b)

Figure 6: Hinge joint model for cover-plate bolted joints. (a) Joints between two modules. (b) Joints between four modules.

in this study by replacing the slotted C-shaped side studs with square hollow tubes $(\square 140 \times 140 \times 5 \mathrm{~mm})$ and increasing the thicknesses of the inner $\mathrm{C}$ studs and the $\mathrm{U}$ tracks from $1 \mathrm{~mm}$ to $2 \mathrm{~mm}$, as shown in Figure 10(b). Using the simplification method in Section 2.1, the strengthened LGSS walls can be simplified to a bar-spring system with an elastic lateral stiffness $\left(K_{e}\right)$ of $8499.99 \mathrm{~N} / \mathrm{mm}$ and a shear capacity $\left(F_{p}\right)$ of $291.17 \mathrm{kN}$. For the benchmark model, the strengthened LGSS walls were employed as shear walls as shown in Figure 11. The filler LGSS walls were ignored because their contribution to stiffness and capacity of structures is very slight. The constant and live loads in common conditions, which are $3.0 \mathrm{kN} / \mathrm{m}^{2}$ and $0.5 \mathrm{kN} / \mathrm{m}^{2}$ in total for the roof and $2.0 \mathrm{kN} / \mathrm{m}^{2}$ and $2.0 \mathrm{kN} / \mathrm{m}^{2}$ for the floors, respectively, were applied to the benchmark modular structure. The self-weight of the LGSS walls could be modelled as linear load with a value of $2.7 \mathrm{kN} / \mathrm{m}$, applied on the frame beams.

\subsubsection{Results of the Benchmark Model. The seismic perfor-} mance of the benchmark model and the reference model (steel frame) under the three selected earthquake waves was evaluated. The earthquake waves were applied along with the $X$-axis, shown in Figure 11(a), which is the axis of the modular structure with a weaker lateral stiffness. The results of the storey drifts $(\theta)$ of the benchmark model and the reference model under frequent and rare earthquake conditions are shown in Figure 12 and summarised in Table 2 . It can be seen that the maximum storey drifts $\left(\theta_{\max }\right)$ were $3.39 \times 10^{-4}, 5.43 \times 10^{-4}$, and $3.25 \times 10^{-4}$ rad under the frequent earthquake conditions (Cape Mendocino wave, Landers wave, and the simulated wave with an adjusted amplitude of $70 \mathrm{gal}$ ). And the maximum storey drifts increased to $19.02 \times 10^{-4}, 32.15 \times 10^{-4}$, and $17.61 \times 10^{-4} \mathrm{rad}$ under the rare earthquake conditions (the recorded and simulated waves with an adjusted amplitude of 400 gal). In other words, the maximum storey drifts were approximate $1 / 1842$ and $1 / 311$ under the frequent and rare earthquake conditions, while the limits are $1 / 300$ and $1 / 50$, respectively, following the relevant provisions of the Chinese Code T/CECS 507: 2018 [39].

The maximum lateral displacements $\left(u_{\mathrm{xmax}}\right)$ of all the frame columns were $8.46 \mathrm{~mm}, 13.98 \mathrm{~mm}$ and $7.25 \mathrm{~mm}$ under the Cape Mendocino wave, Landers wave, and the simulated wave with a wave amplitude of 70 gal (frequent earthquake condition), respectively. With the increasing amplitude to $400 \mathrm{gal}, u_{\max }$ values were increased to $46.73 \mathrm{~mm}(+452 \%), 78.44 \mathrm{~mm}(+461 \%)$, and $46.55 \mathrm{~mm}(+542 \%)$, correspondingly. Meanwhile, the torsional deformations of the frame columns were also considered. The maximum torsional displacements $\left(u_{\mathrm{zmax}}\right)$ were $0.72 \mathrm{~mm}$, $0.84 \mathrm{~mm}$, and $0.69 \mathrm{~mm}$ for the frequent earthquake conditions and $1.53 \mathrm{~mm}, 2.30 \mathrm{~mm}$, and $1.34 \mathrm{~mm}$ for the rare earthquake conditions.

The maximum stress states are extracted and presented in Figure 13. It can be seen that the maximum stresses of the 

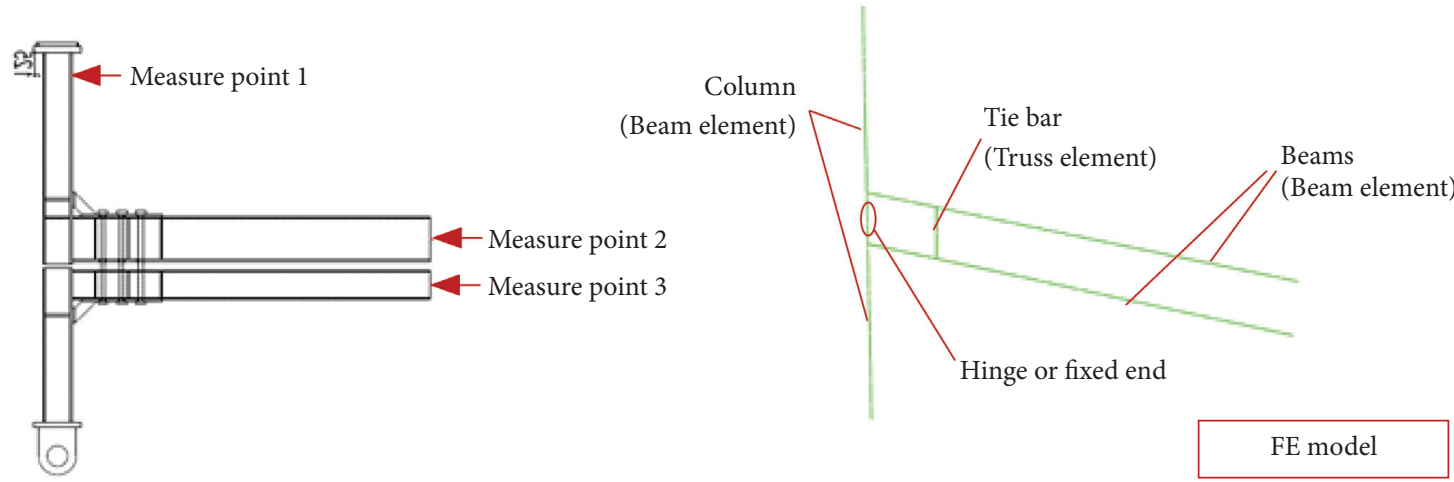

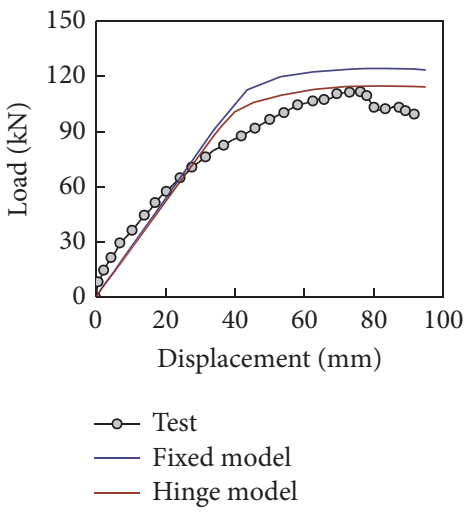

(i) Measure point 1

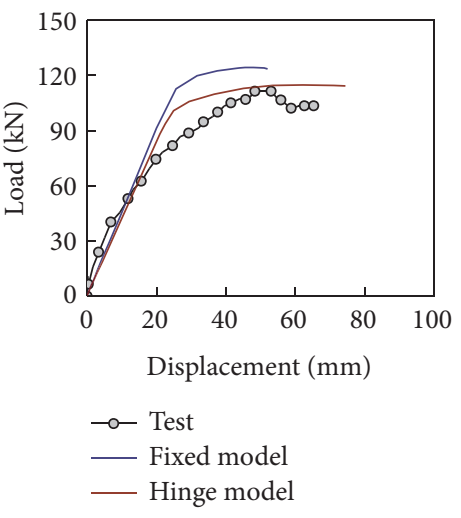

(ii) Measure point 2

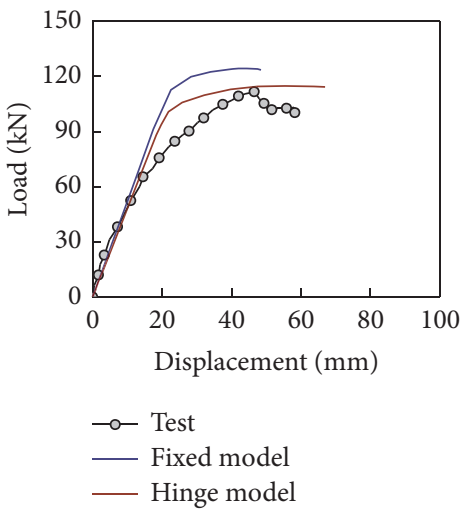

(iii) Measure point 3

(a)
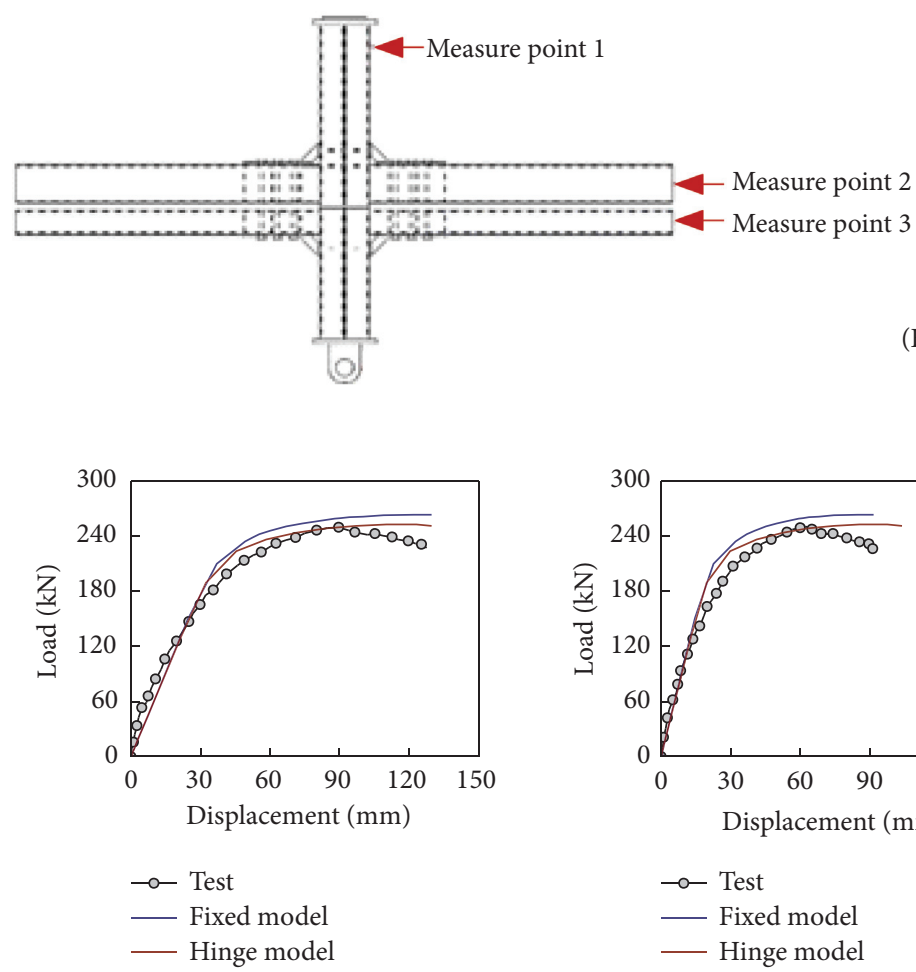

(i) Measure point 1

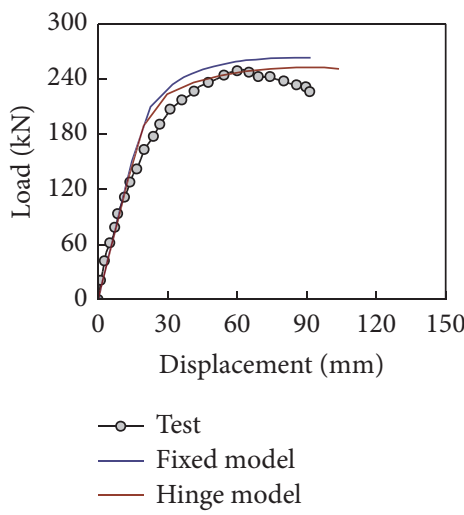

(ii) Measure point 2
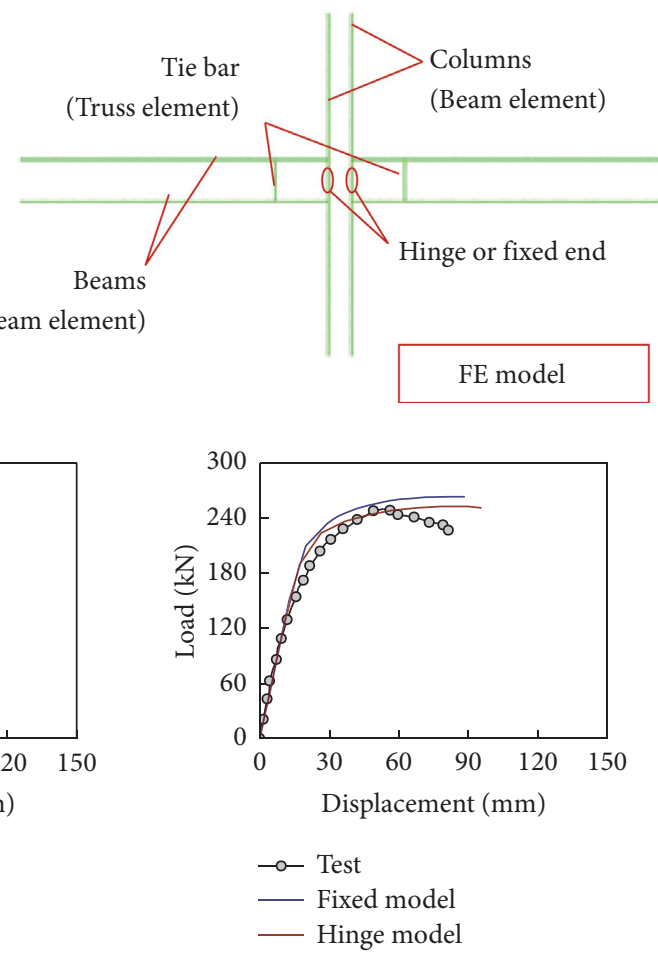

(iii) Measure point 3

(b)

FigURE 7: Simplification for joints [5]. (a) Simplification for joints between two modules. (b) Simplification for joints between four modules. 


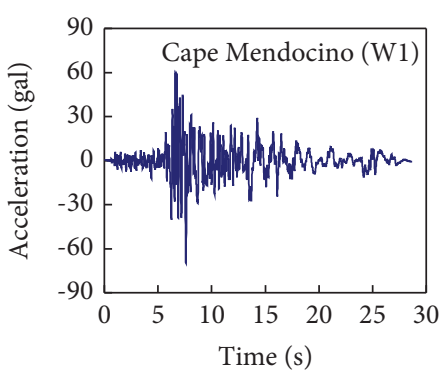

(i) Cape Mendocino wave

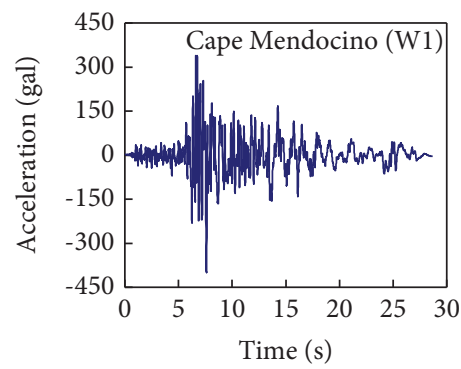

(i) Cape Mendocino wave

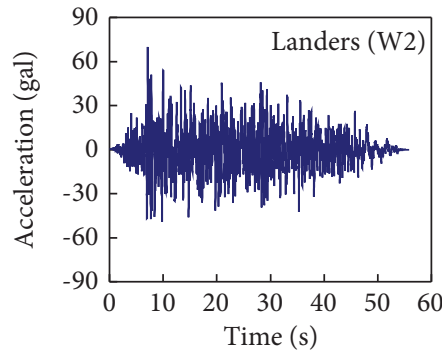

(ii) Landers wave

(a)

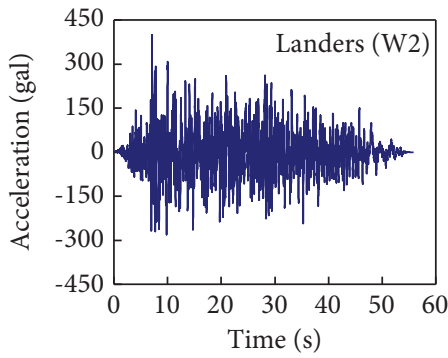

(ii) Landers wave

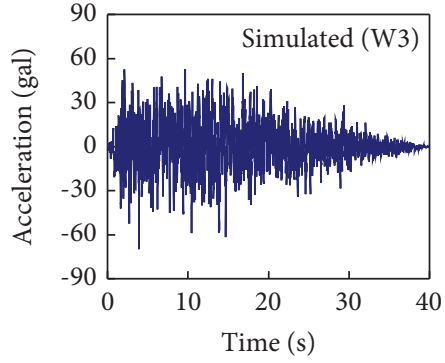

(iii) Simulated wave

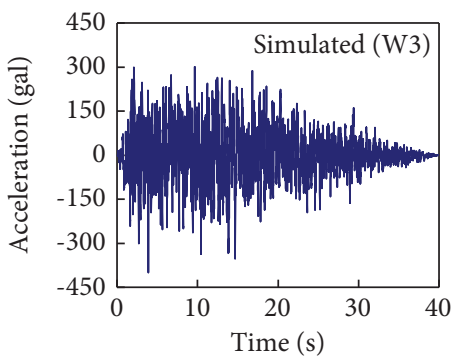

(iii) Simulated wave

(b)

Figure 8: Earthquake waves employed in the FE model. (a) Frequent earthquake conditions (amplitude: 70 gal). (b) Rare earthquake conditions (amplitude: 400 gal).

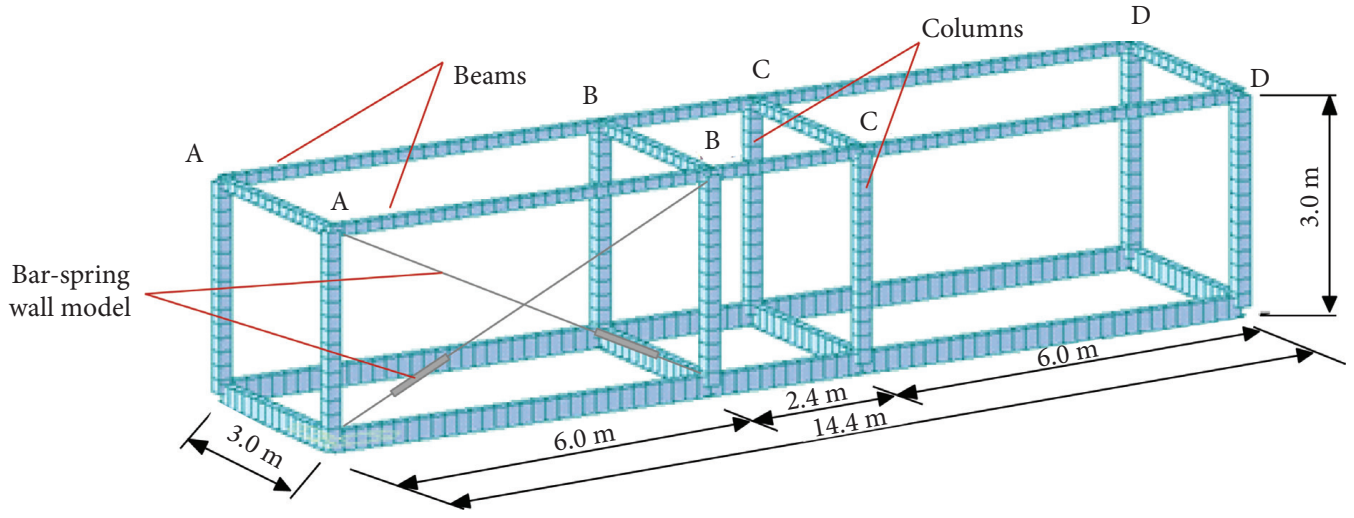

FIGURE 9: Details of the modules considered in the FE model.

structural members were $144.78 \mathrm{MPa}, 151.80 \mathrm{MPa}$, and $143.56 \mathrm{MPa}$ for the three waves under frequent earthquake conditions and 201.59 $\mathrm{MPa}, 240.07 \mathrm{MPa}$, and $189.39 \mathrm{MPa}$ under rare earthquake conditions, which means that all the structural members of the benchmark modular structure remained elastic during the applied seismic loads.

Compared with the reference model, for the three waves under frequent earthquake conditions, the maximum storey drifts of the benchmark model reduced by $-72.88 \%,-58.61 \%$, and $-79.50 \%$, and the average maximum stress reduced by $30.77 \%$, $28.10 \%$, and $32.55 \%$, respectively; under the rare earthquake conditions, the maximum storey drifts of the benchmark model reduced by $-68.29 \%,-50.15 \%$, and $-77.99 \%$, and the average maximum stress reduced by $28.45 \%, 19.47 \%$, and $40.75 \%$, respectively.

Generally, the results show that the 10-storey benchmark modular steel structure model with strengthened LGSS walls possesses excellent lateral stiffness.

\section{Influences of Wall Layouts and Structure Heights on the Seismic Performance}

Based on the developed FE model, parametric studies were conducted to evaluate the influences of wall layouts and structure heights (number of floors) on the seismic performance of modular structures. 


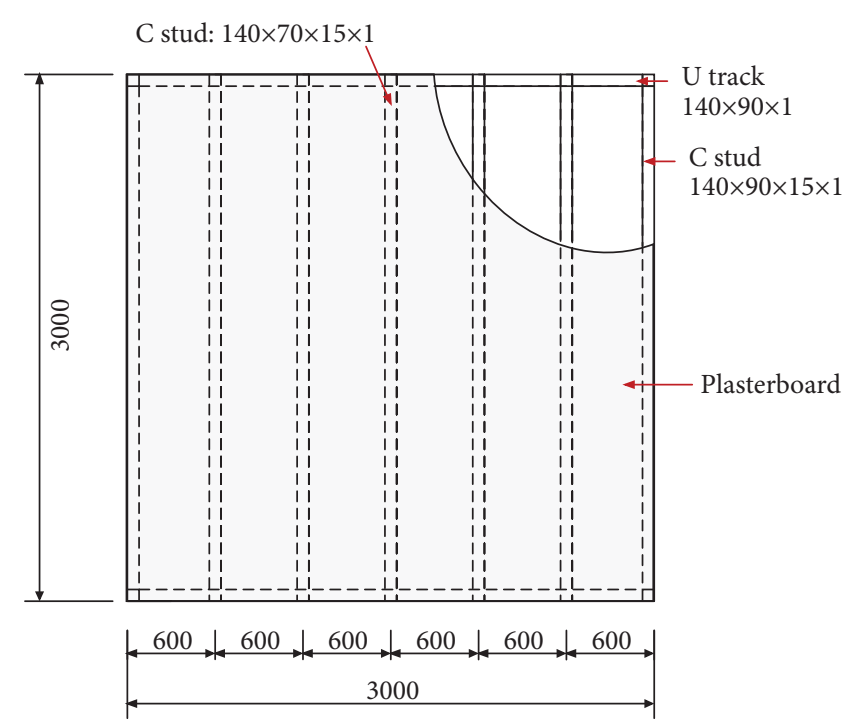

(a)

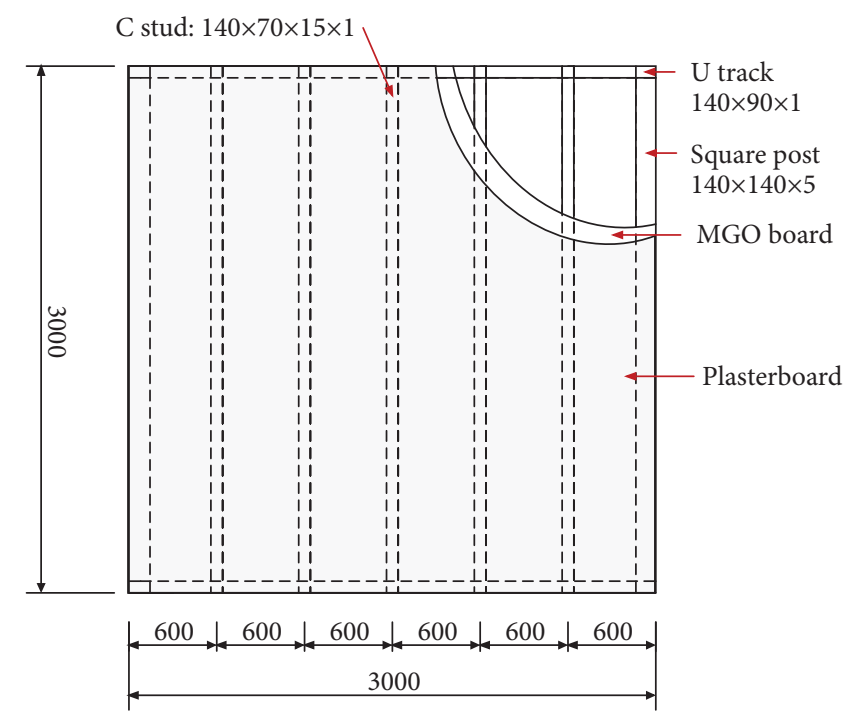

(b)

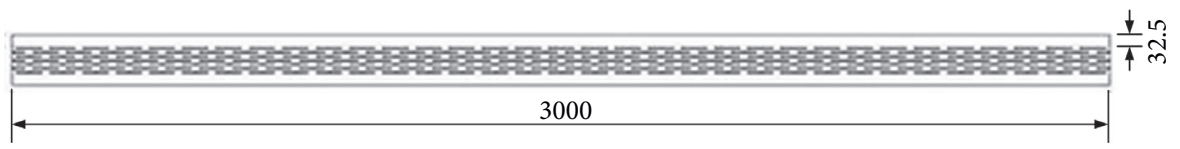

(c)

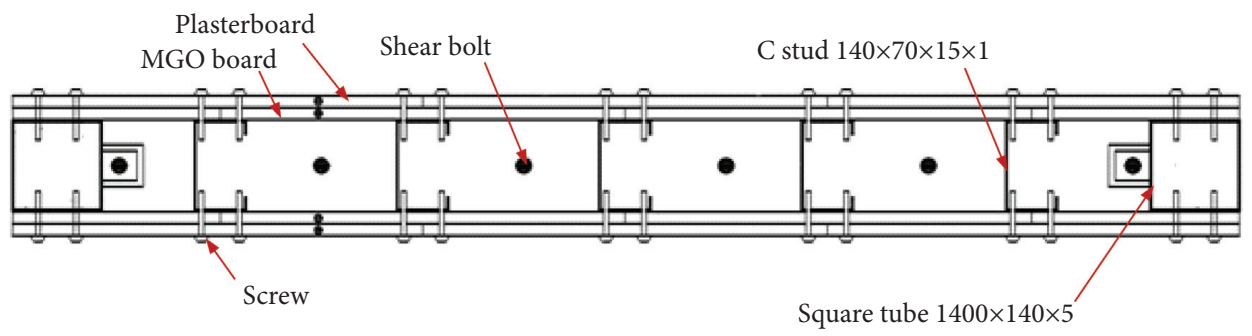

(d)

FIGURE 10: Details of the LGSS walls considered in the FE model. (a) LGSS filler walls. (b) LGSS shear walls. (c) Details of the slotted studs. (d) Cross section of the LGSS shear walls. 

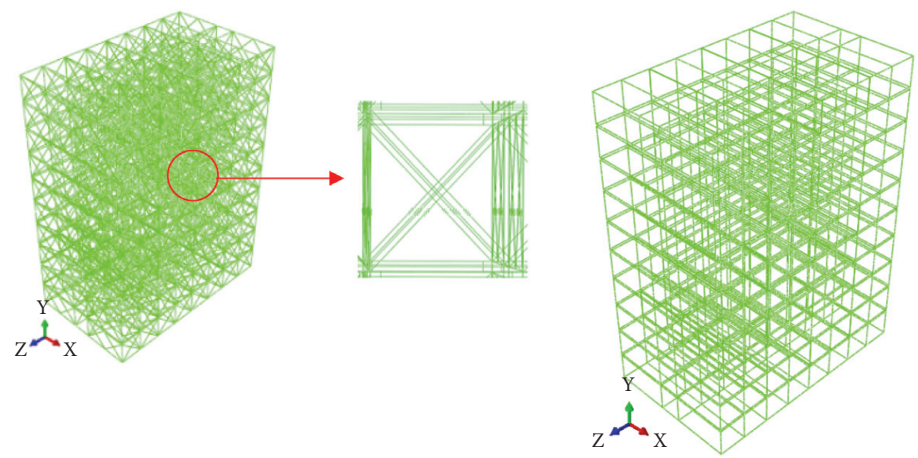

(a)

(b)
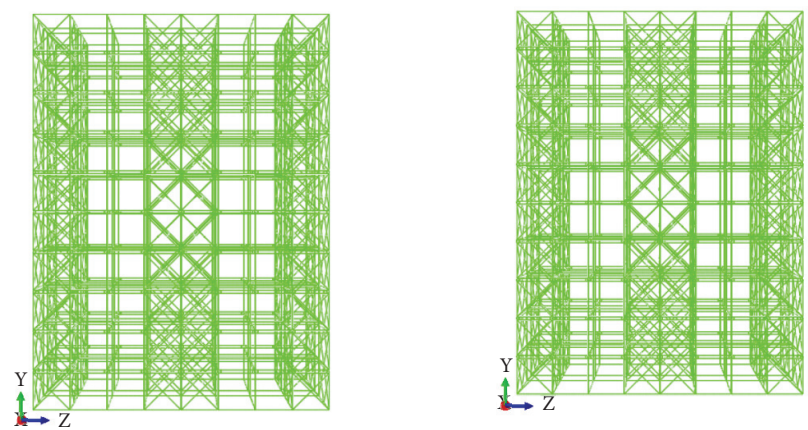

(c)

(d)
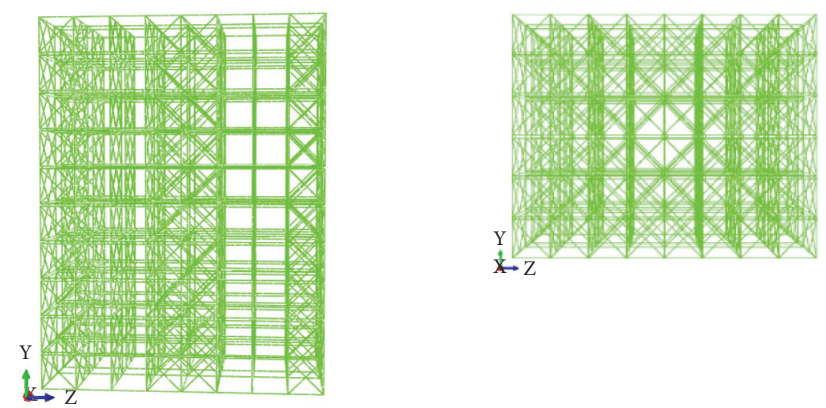

(e)

(f)

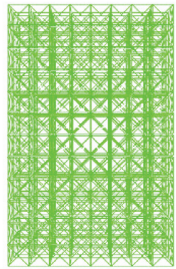

(g)

Figure 11: General view of the FE models. (a) Benchmark model. (b) Reference model (steel frame). (c) Model PA. (d) Model PB. (e) Model PC. (f) Model P6. (g) Model P12.

\subsection{Influences of Wall Layouts}

4.1.1. Presence of the LGSS Shear Walls. To evaluate the contribution of the strengthened LGSS walls to the seismic performance of the benchmark modular structure model, a reference steel frame model without walls was also analysed. The storey drifts $(\theta)$ are also summarised in Table 2 and plotted in Figure 12. A significant increase can be observed when comparing the storey drifts $(\theta)$ obtained from the reference steel frame model with the benchmark modular structure model with strengthened LGSS walls. Under rare earthquake conditions, the maximum storey drifts $\left(\theta_{\max }\right)$ increased by $215.4 \%, 100.6 \%$, and $354.3 \%$, with the LGSS shear walls replaced by the filler walls. Also, the most harmful earthquake wave for the reference steel frame model changed to be the simulated earthquake wave.

The lateral displacement-time history curves are plotted in Figure 14. It can be seen that the amplitude of the lateral 

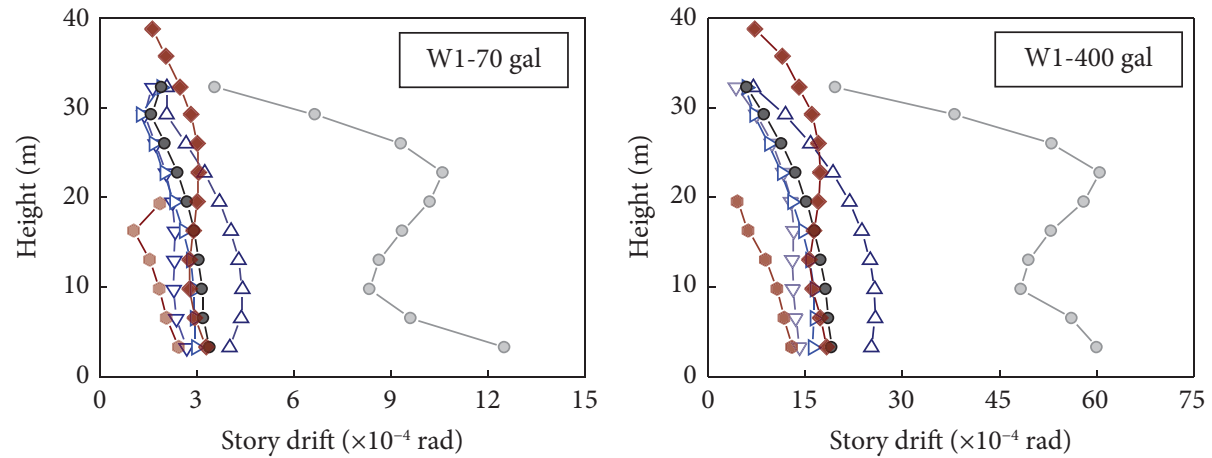

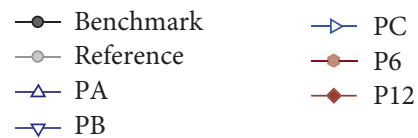

$\rightarrow-\mathrm{PB}$

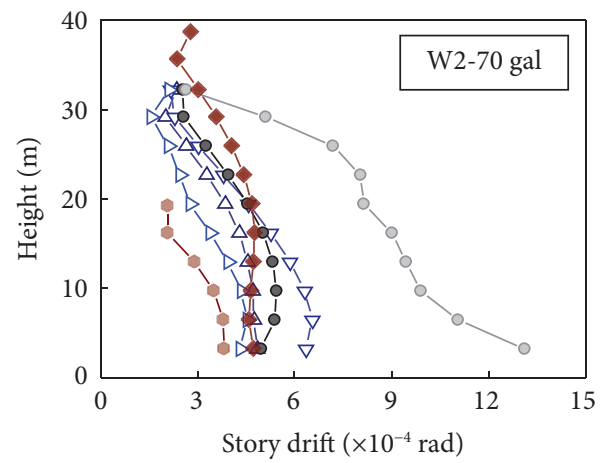

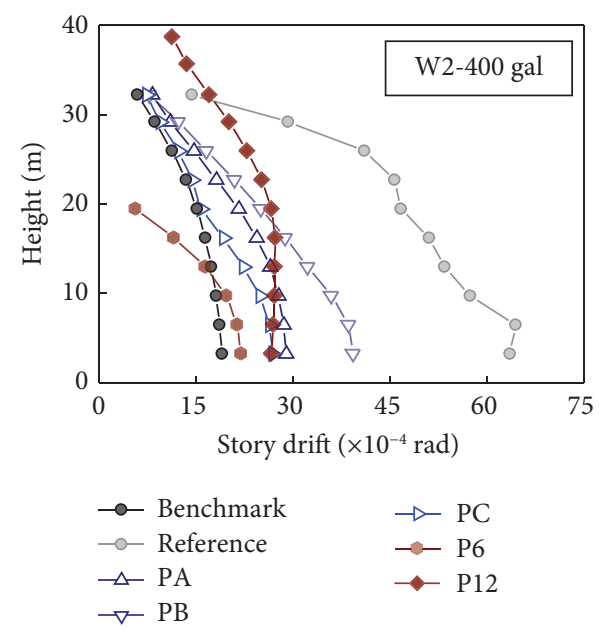

(b)
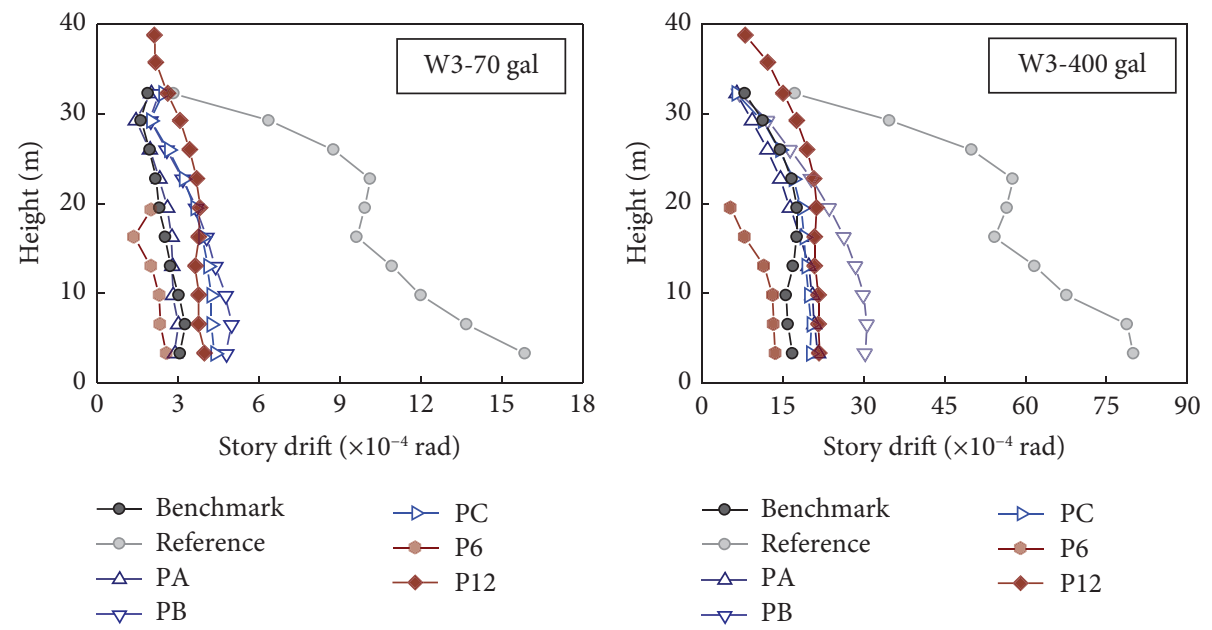

$$
\begin{array}{ll}
\rightarrow-\text { Benchmark } & \rightarrow \text { PC } \\
\multimap-\text { Reference } & \multimap \text { P6 } \\
\neg-\text { PA } & \multimap \text { P12 } \\
\neg-\text { PB } &
\end{array}
$$$$
\begin{array}{ll}
\multimap-\text { Benchmark } & \rightarrow \text { PC } \\
\multimap-\text { Reference } & \multimap \text { P6 } \\
\neg \text { PA } & \multimap \text { P12 } \\
\rightarrow-\text { PB } &
\end{array}
$$

)

(c)

Figure 12: Story drifts of the modular structure models. (a) Story drifts under Cape Mendocino earthquake wave. (b) Story drifts under Landers earthquake wave. (c) Story drifts under simulated earthquake wave. 
TABLE 2: Story-drifts of the modular structures with different layouts $\left(\times 10^{-4} \mathrm{rad}\right)$.

\begin{tabular}{|c|c|c|c|c|c|c|c|c|c|c|c|c|c|c|c|c|c|}
\hline \multirow{2}{*}{ Intensity } & \multirow{2}{*}{ Story } & \multirow{2}{*}{$\begin{array}{l}\text { Height } \\
(\mathrm{mm})\end{array}$} & \multicolumn{3}{|c|}{ Benchmark model } & \multicolumn{3}{|c|}{ Reference model } & \multicolumn{3}{|c|}{ PA model } & \multicolumn{3}{|c|}{ PB model } & \multicolumn{3}{|c|}{ PC model } \\
\hline & & & $\mathrm{W} 1$ & W2 & W3 & W1 & $\mathrm{W} 2$ & W3 & W1 & $\mathrm{W} 2$ & W3 & W1 & $\mathrm{W} 2$ & W3 & $N 1$ & W2 & W3 \\
\hline \multirow{10}{*}{$\begin{array}{l}\text { Frequent } \\
\text { conditions } \\
\text { (70 gal) }\end{array}$} & 1 & 3245 & 3.39 & 4.9 & 3.0 & 12.50 & & 15.85 & 4.00 & & & 2.67 & & & & & .36 \\
\hline & 2 & & 3.20 & 5.37 & 3.25 & & & & & & & & & & & & \\
\hline & 3 & 9735 & 3.16 & 5.43 & 3.03 & 8.33 & & & 4.40 & & & 2.29 & & & & & .21 \\
\hline & 4 & 12980 & 3.06 & 5.31 & 2.71 & 8.63 & 9.45 & & 4.29 & & & 2.30 & & & & & \\
\hline & 5 & 16225 & 2.92 & 5.01 & 2.53 & 9.34 & 9.01 & 9.61 & 4.05 & 4.28 & 2.76 & 2.33 & 5.26 & 4.05 & .58 & 7 & .91 \\
\hline & 6 & 470 & 2.70 & 4.54 & 2.32 & 10.20 & & & 3.69 & & & 2.25 & & & & & 3.63 \\
\hline & 7 & 715 & 2.40 & 3.9 & 2.17 & 10.61 & $8 .($ & & 3.23 & & & & & & & & 3.20 \\
\hline & 8 & 960 & 2.00 & 3.2 & 1.95 & 9.30 & 7.1 & & 2.66 & & & & & & & & .65 \\
\hline & 9 & 205 & 1.58 & 2.5 & 1.61 & 6.64 & 5.0 & & 2.06 & & & 1.37 & & & .25 & & 1.97 \\
\hline & 10 & 205 & 1.90 & 2.53 & 1.88 & 3.55 & 2.64 & 2.83 & 2.06 & 2.34 & 2.00 & 1.63 & & 2.27 & 1.89 & 2.11 & 2.42 \\
\hline \multirow{10}{*}{$\begin{array}{l}\text { Rare } \\
\text { conditions } \\
(400 \text { gal })\end{array}$} & 1 & & 19.02 & 1.73 & 16.81 & 59.98 & 63.59 & 80.00 & 25.16 & 28.99 & 21.57 & 14.21 & & 30.33 & 16.05 & 26.92 & 20.08 \\
\hline & 2 & 190 & 18.64 & 2.15 & 5.90 & 56.21 & & 78.75 & 25.77 & 28.55 & 20.86 & 13.60 & & 30. & 16.43 & & 20.27 \\
\hline & 3 & 9735 & 18.16 & 31.20 & 15.59 & 48.35 & 57.48 & 67.62 & 25.73 & 27.75 & 20.47 & 13.21 & 35.99 & 29.96 & 16.39 & & 19.80 \\
\hline & 4 & 12980 & 17.38 & 29.80 & 16.94 & 49.46 & 53.43 & 61.70 & 24.97 & 26.47 & 19.75 & 13.09 & 32.37 & 28.63 & 15.73 & 22.30 & 19.32 \\
\hline & 5 & 16225 & 16.48 & 27.68 & 17.61 & 52.98 & 51.09 & 54.24 & 23.75 & 24.36 & 18.33 & 13.30 & 28.84 & 26.47 & 14.57 & 19.23 & 18.95 \\
\hline & 6 & 19470 & 15.22 & 25.07 & 17.57 & 58.04 & & & 21.82 & & & 12.88 & & & & & 18.41 \\
\hline & 7 & 22715 & 13.49 & 21.86 & 16.61 & 60.46 & 45.75 & 57.65 & 19.16 & 18.20 & 14.58 & 11.74 & 21.00 & 20.31 & 11.26 & 14.35 & 16.92 \\
\hline & 8 & 25960 & 11.27 & 18.13 & 14.52 & 53.07 & 41.03 & 49.96 & 15.79 & 14.68 & 12.17 & 9.91 & 16.66 & 16.45 & 9.29 & 12.30 & 14.45 \\
\hline & 9 & 29205 & 8.68 & 13.98 & 11.33 & 38.14 & 29.28 & 34.78 & 11.93 & 10.98 & 9.23 & 7.54 & 12.35 & 12.29 & 7.03 & 9.44 & 11.16 \\
\hline & 10 & 32205 & 5.97 & 9.4 & 7.98 & 19.57 & 14.36 & 17.31 & 6.90 & 8.28 & 6.37 & 4.39 & 7.88 & 6.98 & 5.84 & 7.30 & 6.25 \\
\hline
\end{tabular}

Note. The three earthquake waves (i.e., the recorded Cape Mendocino wave, Landers wave, and the simulated wave) are abbreviated to W1, W2, and W3 in the table, respectively. And the maximum values are marked in bold.

deformations increased and the vibrations were more vital for the modular without the LGSS shear walls. Moreover, the maximum torsional displacements $\left(u_{\mathrm{zmax}}\right)$ and the maximum stress of the reference model were also raised, as summarised in Table 3. The increases of these critical responses indicated that the seismic performance of the studied modular structure could be improved by employing the LGSS shear walls.

4.1.2. Layouts of the LGSS Shear Walls. Commonly, to meet the requirements of practical use, some of the walls have to be designed with holes for doors and windows or be removed for achieving open space. Thus, the layouts of the shear walls need to be considered. Three layout plans, named Model PA, Model PB, and Model PC, were modelled in this section, as shown in Figure 11.

The storey drifts $(\theta)$ of these models are summarised in Table 2 and plotted in Figure 12. It can be seen that the modelled modular structure using the three layout plans still possessed good lateral resistance compared to the reference steel frame model without shear walls, and the maximum storey drifts $\left(\theta_{\max }\right)$ were only increased slightly (1.2\% average) compared to the benchmark model $\left(32.15 \times 10^{-4} \mathrm{rad}\right)$. Under rare earthquake conditions, the maximum storey drifts $\left(\theta_{\max }\right)$ were $28.99 \times 10^{-4} \mathrm{rad}$, $39.42 \times 10^{-4} \mathrm{rad}$, and $26.92 \times 10^{-4} \mathrm{rad}$, respectively, for Model PA, Model PB, and Model PC. Compared with the reference model $\left(64.49 \times 10^{-4} \mathrm{rad}\right), \theta_{\max }$ reduced by $55.05 \%$, 38.87\%, and $58.26 \%$, respectively. As summarised in Table 3, the maximum lateral displacements $\left(u_{\mathrm{xmax}}\right)$ of the three models were $86.43 \mathrm{~mm}, 95.25 \mathrm{~mm}$ and $54.95 \mathrm{~mm}$, respectively for Model PA, Model PB and Model PC. Compared with the reference model $(138.78 \mathrm{~mm}), u_{\mathrm{xmax}}$ reduced by $37.72 \%, 31.37 \%, 60.40 \%$, respectively. Moreover, the maximum stress values of $\mathrm{t} 5 *$ he models were $328.1 \mathrm{MPa}, 328.8 \mathrm{MPa}$, and $347.1 \mathrm{MPa}$ under rare earthquake conditions, as shown in Table 3. Compared with the reference model $(298.4 \mathrm{MPa})$, the maximum stress increased by $9.95 \%, 10.19 \%$, and $16.32 \%$, respectively. Generally, based on the key indexes, that is, the maximum storey drifts $\left(\theta_{\max }\right)$ and the maximum displacements $\left(u_{\mathrm{xmax}}\right)$, the third layout plan (model PC) was recommended. However, based on the stress states, the first and the second plans are still worth being considered.

4.2. Influence of Structure Heights (Number of Floors). Two more modular structure models with six floors and twelve floors were analysed to investigate the influence of the building height on the dynamic performance of modular steel structures with LGSS shear walls subjected to seismic loads. These two models were named P6 and P12, respectively, as shown in Figure 11, in accordance with the numbers of the floors. The storey drifts $(\theta)$ of these models are summarised in Table 4 and plotted in Figure 12. The maximum lateral displacements $\left(u_{\mathrm{xmax}}\right)$, the maximum torsional displacements $\left(u_{\mathrm{z} \max }\right)$ and the maximum stress of the assembled structural members were presented in Table 3. With the increasing structural heights from $19,225 \mathrm{~mm}$ to $38,695 \mathrm{~mm}$ (the number of floors increased from six to twelve), the maximum storey drifts, the maximum lateral displacements, and the maximum stress of the structural members under Landers earthquake wave increased by $23.9 \%, 170.6 \%$, and $123.0 \%$, respectively. It can be seen that these key response indexes were all tended to increase with the increasing structural heights. However, some intermediate floors' storey drifts $(\theta)$ may decrease for higher modular buildings. 

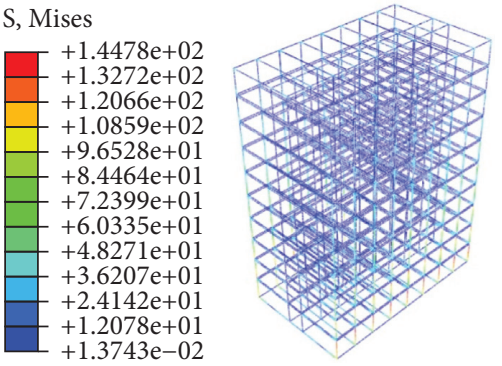

(a)

S, Mises Multiple section points (Avg: 75\%)
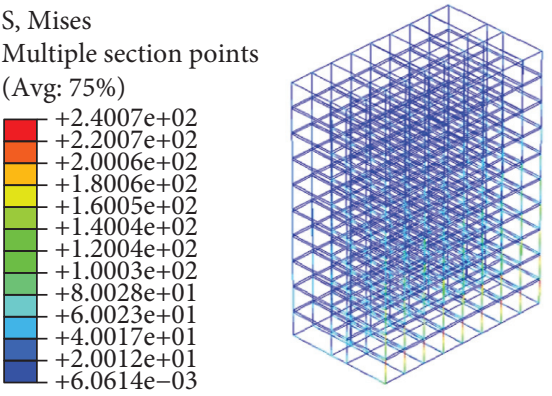

(d)
S, Mises

Multiple section points (Avg: 75\%)

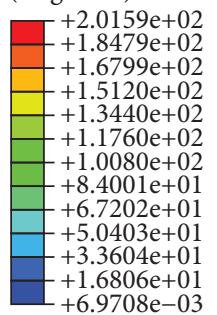

$+6.9708 \mathrm{e}-03$

S, Mises

Multiple section points (Avg: 75\%)

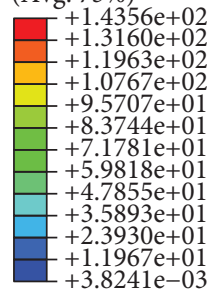

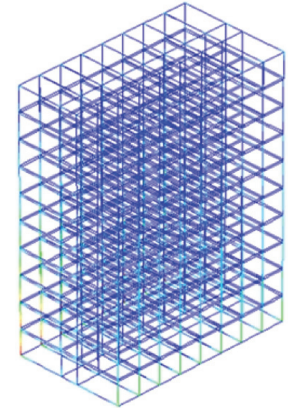

(b)

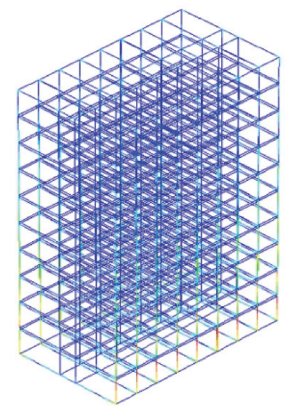

S, Mises

Multiple section points (Avg: 75\%)
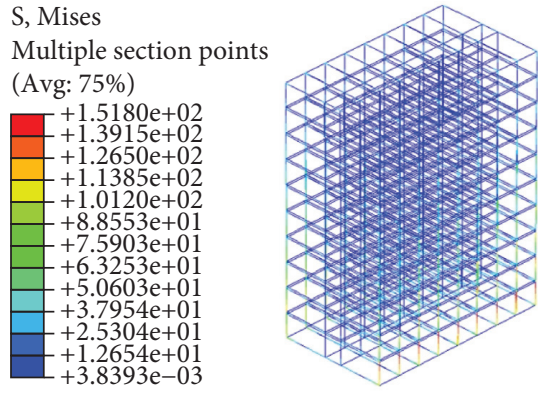

(c)

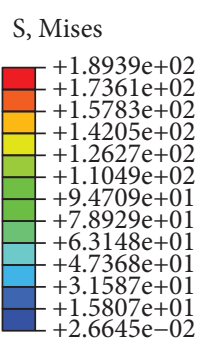

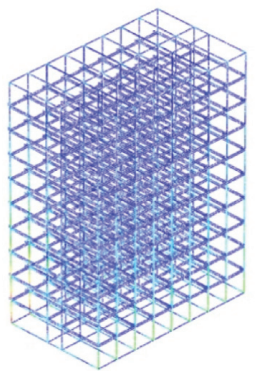

(f)

Figure 13: Stress states of the benchmark model under seismic loads. (a) Cape Mendocino wave (amplitude: 70 gal). (b) Cape Mendocino wave (amplitude: 400 gal). (c) Landers wave (amplitude: 70 gal). (d) Landers wave (amplitude: 400 gal). (e) Simulated wave (amplitude: 70 gal). (f) Simulated wave (amplitude: 400 gal).

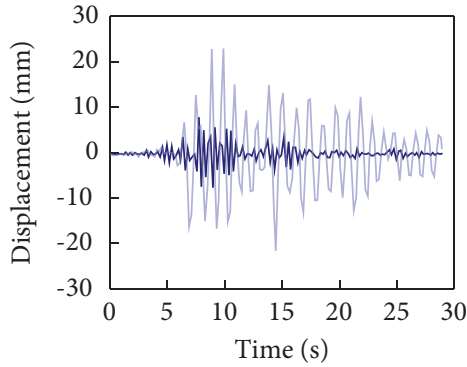

(a)

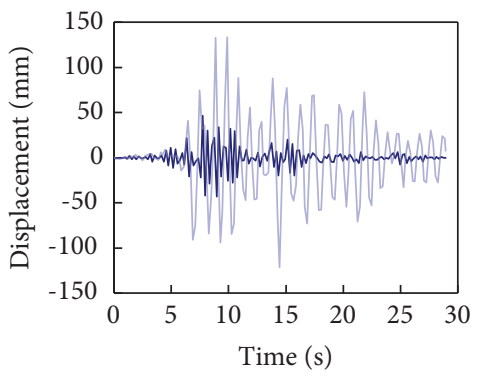

(d)

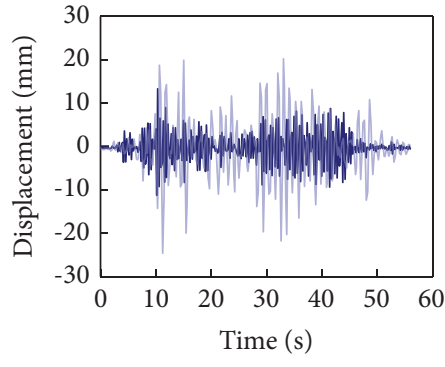

(b)

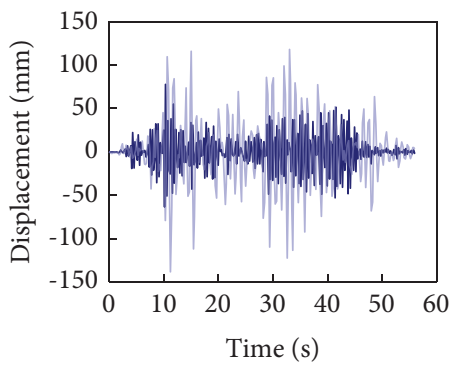

(e)

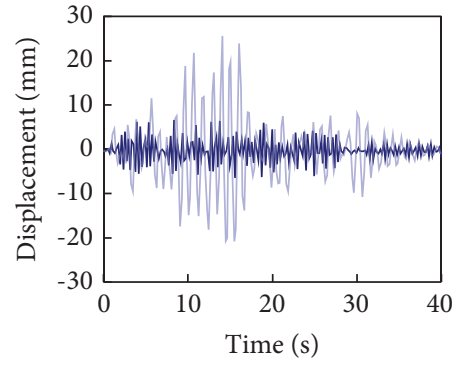

(c)

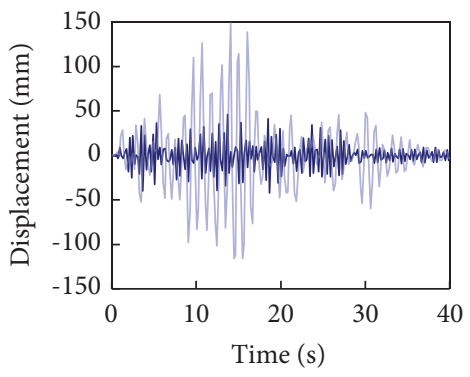

(f)

Figure 14: Lateral displacement-time history curves (dark blue: benchmark model, light blue: reference model). (a) Cape Mendocino wave (amplitude: 70 gal). (b) Landers wave (amplitude: 70 gal). (c) Simulated wave (amplitude: 70 gal). (d) Cape Mendocino wave (amplitude: $400 \mathrm{gal})$. (e) Landers wave (amplitude: $400 \mathrm{gal}$ ). (f) Simulated wave (amplitude: $400 \mathrm{gal}$ ). 


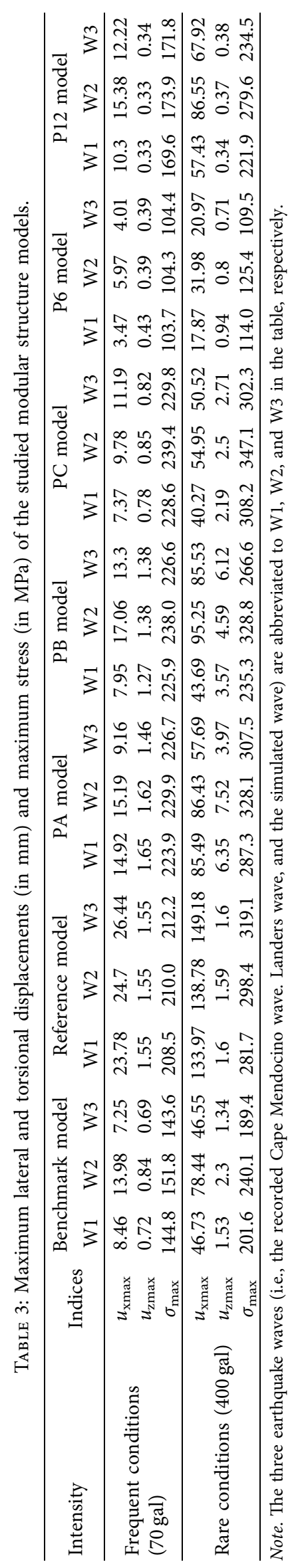


TABLE 4: Story drifts of the modular structures with different structure heights $\left(\times 10^{-4} \mathrm{rad}\right)$.

\begin{tabular}{|c|c|c|c|c|c|c|c|c|c|c|c|c|c|c|}
\hline \multirow{2}{*}{ Intensity } & \multirow{2}{*}{ Story } & \multirow{2}{*}{ Height (mm) } & \multicolumn{3}{|c|}{ Benchmark model } & \multicolumn{3}{|c|}{ Reference model } & \multicolumn{3}{|c|}{ P6 model } & \multicolumn{3}{|c|}{ P12 model } \\
\hline & & & W1 & W2 & W3 & $\mathrm{W} 1$ & W2 & W3 & $\mathrm{W} 1$ & W2 & W3 & W1 & W2 & W3 \\
\hline \multirow{12}{*}{$\begin{array}{l}\text { Frequent conditions } \\
\text { ( } 70 \text { gal) }\end{array}$} & 1 & 3245 & 3.39 & 4.96 & 3.07 & 12.50 & 13.12 & 15.85 & 2.44 & 3.80 & 2.57 & 3.30 & 4.73 & 3.97 \\
\hline & 2 & 6490 & 3.20 & 5.37 & 3.25 & 9.61 & 11.06 & 13.68 & 2.06 & 3.78 & 2.34 & 2.94 & 4.59 & 3.76 \\
\hline & 3 & 9735 & 3.16 & 5.43 & 3.03 & 8.33 & 9.91 & 12.01 & 1.85 & 3.49 & 2.31 & 2.77 & 4.64 & 3.76 \\
\hline & 4 & 12980 & 3.06 & 5.31 & 2.71 & 8.63 & 9.45 & 10.93 & 1.54 & 2.89 & 2.00 & 2.78 & 4.73 & 3.65 \\
\hline & 5 & 16225 & 2.92 & 5.01 & 2.53 & 9.34 & 9.01 & 9.61 & 1.06 & 2.07 & 1.36 & 2.90 & 4.77 & 3.77 \\
\hline & 6 & $\begin{array}{c}19470 \\
\left(19225^{*}\right)\end{array}$ & 2.70 & 4.54 & 2.32 & 10.20 & 8.13 & 9.94 & 1.86 & 2.07 & 1.99 & 3.01 & 4.68 & 3.81 \\
\hline & 7 & 22715 & 2.40 & 3.94 & 2.17 & 10.61 & 8.03 & 10.12 & & & & 3.06 & 4.43 & 3.69 \\
\hline & 8 & 25960 & 2.00 & 3.26 & 1.95 & 9.30 & 7.19 & 8.75 & & & & 3.01 & 4.05 & 3.43 \\
\hline & 9 & 29205 & 1.58 & 2.55 & 1.61 & 6.64 & 5.09 & 6.35 & & & & 2.82 & 3.57 & 3.06 \\
\hline & 10 & $\begin{array}{c}32205 \\
\left(32450^{*}\right)\end{array}$ & 1.90 & 2.53 & 1.88 & 3.55 & 2.64 & 2.83 & & & & 2.48 & 3.02 & 2.61 \\
\hline & 11 & 35695 & & & & & & & & & & 2.05 & 2.37 & 2.16 \\
\hline & 12 & 38695 & & & & & & & & & & 1.63 & 2.77 & 2.11 \\
\hline \multirow{12}{*}{ Rare conditions ( 400 gal) } & 1 & 3245 & 19.02 & 31.73 & 16.81 & 59.98 & 63.59 & 80.00 & 12.95 & 21.99 & 13.68 & 18.44 & 26.67 & 21.76 \\
\hline & 2 & 6490 & 18.64 & 32.15 & 15.90 & 56.21 & 64.49 & 78.75 & 11.81 & 21.43 & 13.39 & 17.42 & 26.98 & 21.64 \\
\hline & 3 & 9735 & 18.16 & 31.20 & 15.59 & 48.35 & 57.48 & 67.62 & 10.67 & 19.75 & 13.26 & 16.19 & 27.19 & 21.62 \\
\hline & 4 & 12980 & 17.38 & 29.80 & 16.94 & 49.46 & 53.43 & 61.70 & 8.88 & 16.42 & 11.52 & 15.68 & 27.16 & 20.94 \\
\hline & 5 & 16225 & 16.48 & 27.68 & 17.61 & 52.98 & 51.09 & 54.24 & 6.27 & 11.61 & 8.02 & 16.44 & 27.24 & 20.95 \\
\hline & 6 & $\begin{array}{c}19470 \\
\left(19225^{*}\right)\end{array}$ & 15.22 & 25.07 & 17.57 & 58.04 & 46.73 & 56.49 & 4.52 & 5.70 & 5.31 & 17.06 & 26.65 & 21.32 \\
\hline & 7 & 22715 & 13.49 & 21.86 & 16.61 & 60.46 & 45.75 & 57.65 & & & & 17.35 & 25.16 & 20.87 \\
\hline & 8 & 25960 & 11.27 & 18.13 & 14.52 & 53.07 & 41.03 & 49.96 & & & & 17.09 & 22.89 & 19.57 \\
\hline & 9 & 29205 & 8.68 & 13.98 & 11.33 & 38.14 & 29.28 & 34.78 & & & & 16.06 & 20.11 & 17.62 \\
\hline & 10 & $\begin{array}{c}32205 \\
\left(32450^{*}\right)\end{array}$ & 5.97 & 9.4 & 7.98 & 19.57 & 14.36 & 17.31 & & & & 14.14 & 17.02 & 15.16 \\
\hline & 11 & 35695 & & & & & & & & & & 11.45 & 13.63 & 12.26 \\
\hline & 12 & 38695 & & & & & & & & & & 7.23 & 11.28 & 8.06 \\
\hline
\end{tabular}

Note. The three earthquake waves (i.e., the recorded Cape Mendocino wave, Landers wave, and the simulated wave) are abbreviated to W1, W2, and W3 in the table, respectively. And the maximum values are marked in bold.

\section{Conclusion}

This paper numerically investigated the seismic performance of modular steel structures with LGSS walls. A finite element model was developed and parametric studies were then conducted to investigate the influences of the layouts of the LGSS shear walls and structure heights on the lateral stiffness, the deformation modes, and the stress states of the modular steel structures. Based on the results, the following conclusions can be drawn:

(1) The simplified bar-spring model proposed for LGSS walls and the hinge joint assumption were verified using existing experimental studies. The comparison of the experimental and the numerical results showed that the simplified model could characterise the lateral resisting behaviour of LGSS shear walls, and the hinge assumption could balance both accuracy and efficiency.

(2) A FE model was developed to investigate modular steel structures' performance under seismic loads. Compared with the steel frame model, the maximum storey drifts, the maximum lateral displacements, the maximum torsional displacements and the maximum stress of the modular steel structure model decreased notably, indicating that the benchmark modular steel structure possessed good lateral resistance.

(3) Parametric studies were then conducted, in which the LGSS shear wall layouts and the structural heights (number of floors) were included. The results showed that these three studied models still possessed good lateral stiffness. The maximum torsional displacement tended to rise when increasing the structural heights.

\section{Data Availability}

All the data generated or analysed during this study are included in this published article and also, the datasets analysed to support the findings of this study are available from the corresponding author upon request.

\section{Conflicts of Interest}

The authors declare that they have no conflicts of interest regarding the publication of this study.

\section{Acknowledgments}

The research in this paper was sponsored by the Chinese National Engineering Research Centre for Steel Construction (Grant no. YZB2018Ky02). 


\section{References}

[1] H. T. Thai, T. Ngo, and B. Uy, "A review on modular construction for high-rise buildings," Structures, vol. 28, pp. 1265-1290, 2020.

[2] A. W. Lacey, W. Chen, H. Hao, and K. Bi, "Structural response of modular buildings-an overview," Journal of Building Engineering, vol. 16, pp. 45-56, 2108.

[3] J. Y. R. Liew, Y. S. Chua, and Z. Dai, "Steel concrete composite systems for modular construction of high-rise buildings," Structures, vol. 21, pp. 135-149, 2019.

[4] S. Shan, D. Looi, Y. Cai, and P. Ma, "Engineering modular integrated construction for high-rise building: a case study in Hong Kong," Proceedings of the Institution of Civil Engineers-Civil Engineering, vol. 172, no. 6, pp. 51-57, 2019.

[5] Z. Chen, J. Liu, Y. Yu, C. Zhou, and R. Yan, "Experimental study of an innovative modular steel building connection," Journal of Constructional Steel Research, vol. 139, pp. 69-82, 2017.

[6] R. Sanches, O. Mercan, and B. Roberts, "Experimental investigations of vertical post-tensioned connection for modular steel structures," Engineering Structures, vol. 175, pp. 776-789, 2018.

[7] X. M. Dai, L. Zong, Y. Ding, and Z. X. Li, "Experimental study on seismic behavior of a novel plug-in self-lock joint for modular steel construction," Engineering Structures, vol. 181, pp. 143-164, 2019.

[8] A. W. Lacey, W. Chen, H. Hao, and K. Bi, "New interlocking inter-module connection for modular steel buildings: experimental and numerical studies," Engineering Structures, vol. 198, Article ID 109465, 2019.

[9] A. W. Lacey, W. Chen, H. Hao, and K. Bi, "Effect of intermodule connection stiffness on structural response of a modular steel building subjected to wind and earthquake load," Engineering Structures, vol. 213, Article ID 110628, 2020.

[10] R. Li, "Research on structural performance of light-weight steel modular construction," Master's thesis, Beijing Jiaotong University, Beijing, China, 2018.

[11] X. C. Liu, S. H. Pu, A. L. Zhang et al., "Static and seismic experiment for bolted-welded joint in modularised prefabricated steel structure," Journal of Constructional Steel Research, vol. 115, pp. 417-433, 2015.

[12] Q. Wang and M. Su, "Stability study on sway modular steel structures with semi-rigid connections," Thin-Walled Structures, vol. 161, Article ID 107529, 2021.

[13] M. Farajian, P. Sharafi, and K. Kildashti, "The influence of inter-module connections on the effective length of columns in multi-storey modular steel frames," Journal of Constructional Steel Research, vol. 177, Article ID 106450, 2021.

[14] A. W. Lacey, W. Chen, H. Hao, and K. Bi, "Review of bolted inter-module connections in modular steel buildings," Journal of Building Engineering, vol. 23, pp. 207-219, 2019.

[15] W. K. Yu, K. F. Chung, and S. L. Chan, "Structural instability of multi-storey door-type modular steel scaffolds," Engineering Structures, vol. 26, pp. 867-881, 2004.

[16] C. D. Annan, M. A. Youssef, and M. H. Ei Naggar, "Experimental evaluation of the seismic performance of modular steel-braced frames," Engineering Structures, vol. 31, pp. 1435-1446, 2009.

[17] Y. Yu and Z. Chen, "Rigidity of corrugated plate sidewalls and its effect on the modular structural design," Engineering Structures, vol. 175, pp. 191-200, 2018.
[18] Z. Chen, K. Khan, A. Khan, K. Javed, and J. Liu, "Exploration of the multidirectional stability and response of prefabricated volumetric modular steel structures," Journal of Constructional Steel Research, vol. 184, Article ID 106826, 2021.

[19] C. D. Annan, M. A. Youssef, and M. H. El Naggar, "Seismic vulnerability assessment of modular steel buildings," Journal of Earthquake Engineering, vol. 13, pp. 1065-1088, 2009.

[20] A. Fathieh and O. Mercan, "Seismic evaluation of modular steel buildings," Engineering Structures, vol. 122, pp. 83-92, 2016.

[21] Y. Liu, Z. Chen, J. Liu, Y. Bai, X. Zhong, and X. Wang, "Lateral stiffness evaluation on corner-supported thin walled modular steel structures," Thin-Walled Structures, vol. 157, Article ID 106967, 2020.

[22] J. Liu, Z. Chen, Y. Liu, Y. Bai, and X. Zhong, "Full-scale corner-supported modular steel structures with vertical intermodule connections under cyclic loading," Journal of Building Engineering, vol. 44, Article ID 103269, 2021.

[23] L. Chen, R. Tremblay, and L. Tirca, "Modular tied eccentrically braced frames for improved seismic response of tall buildings," Journal of Constructional Steel Research, vol. 155, pp. 370-384, 2019.

[24] Y. S. Chua, J. Y. R. Liew, and S. D. Pang, "Modelling of connections and lateral behavior of high-rise modular steel buildings," Journal of Constructional Steel Research, vol. 166, Article ID 105901, 2020.

[25] F. Shi, H. Wang, L. Zong, Y. Ding, and J. Su, "Seismic behavior of high-rise modular steel constructions with various module layouts," Journal of Building Engineering, vol. 31, Article ID 101396, 2020.

[26] N. Usefi, P. Sharafi, M. Mortazavi, H. Ronagh, and B. Samali, "Structural performance and sustainability assessment of hybrid-cold formed modular steel frame," Journal of Building Engineering, vol. 34, Article ID 101895, 2021.

[27] R. Sanches, J. Tao, A. Fathieh, and O. Mercan, "Investigation of the seismic performance of braced low-, mid- and high-rise modular steel building prototypes," Engineering Structures, vol. 234, Article ID 111986, 2021.

[28] E. F. Deng, L. Zong, Y. Ding et al., "Seismic performance of mid-to-high rise modular steel construction-a critical review," Thin-Walled Structures, vol. 155, Article ID 106924, 2020.

[29] S. G. Hong, B. H. Cho, K. S. Chung, and J. H. Moon, "Behavior of framed modular building system with double skin steel panels," Journal of Constructional Steel Research, vol. 67, pp. 936-946, 2011.

[30] X. M. Dai, Y. Ding, L. Zong, E. F. Deng, N. You, and Y. Chen, "Experimental study on seismic behavior of steel strip reinforced CSPSWs in modular building structures," Journal of Constructional Steel Research, vol. 151, pp. 228-237, 2018.

[31] Y. Ding, E. F. Deng, L. Zong, X. M. Dai, N. You, and Y. Chen, "Cyclic tests on corrugated steel plate shear walls with openings in modularised-constructions," Journal of Constructional Steel Research, vol. 138, pp. 675-691, 2017.

[32] M. Rashidi, P. Sharafi, M. Alembagheri, A. Bigdeli, and B. Samali, "Operational model analysis, testing and modelling of prefabricated steel modules with different LSF composite walls," Materials, vol. 13, p. 5816, 2020.

[33] J. Ye, X. Wang, H. Jia, and M. Zhao, "Cyclic performance of cold-formed steel shear walls sheathed with double-layer wallboards on both sides," Thin-Walled Structures, vol. 92, pp. 146-159, 2015.

[34] Y. Geng, Y. Wang, J. Ding, and W. Xu, "Mechanical behavior of connections between out-hung light-gauge steel stud walls 
and steel frames," Journal of Building Structures, vol. 37, no. 6, pp. 141-150, 2016, in Chinese.

[35] A. W. Lacey, W. Chen, H. Hao, and K. Bi, "Simplified structural behaviours of post-tensioned inter-module connection for modular buildings," Journal of Constructional Steel Research, vol. 175, Article ID 106347, 2020.

[36] A. W. Lacey, W. Chen, H. Hao, and K. Bi, "Lateral behaviour of modular steel building with simplified models of new intermodule connections," Engineering Structures, vol. 236, Article ID 112103, 2021

[37] Japan Iron and Steel Federation, Design Manual for Thin-Slab Lightweight Steel Buildings, Japan Iron and Steel Federation, Tokyo, Japan, in Japanese, 2001.

[38] GB 50011-2010, Code for Seismic Design of Buildings, Ministry of Housing and Urban-Rural Development of the People's Republic of China, Beijing, China, 2016, in Chinese.

[39] T./CECS 507-2018, Technical Specification for Steel Modular Buildings, China Engineering Construction Standardization Association (CECS), Beijing, China, 2018, in Chinese. 